\title{
La prensa y los españoles separatistas en los albores de la guerra independentista de Cuba
}

\author{
Aldana Ratuschny* \\ Recibido: 14 de abril de 2020 \\ Dictaminado: 26 de agosto de 2020 \\ Aceptado: 30 de octubre de 2020
}

\section{REsUMEN}

Este artículo tematiza sobre el papel de la prensa durante la lucha independentista cubana, en relación con la participación de españoles en la contienda a favor de la emancipación de Cuba. La fuente principal de este estudio es el periódico Patria, fundado por José Martí, al que consideramos principal exponente de la prensa cubana revolucionaria en tiempos de preparación de la guerra anticolonial. El objetivo específico consiste en analizar el discurso que el medio dirige particularmente a la comunidad hispana, observando los modos de interpelación y argumentos discursivos que desarrolla para convencer a los propios españoles de apoyar la independencia de la Gran Antilla y su separación de España. Al mismo tiempo, se plantea un diálogo imaginario, un debate periodístico e ideológico, entre Patria (prensa revolucionaria) y la prensa peninsular oficial (liberal-conservadora), que, a través de argumentos contrarios, también se disputaba la participación de la comunidad ibérica en la guerra de Cuba. El recorte temporal que se selecciona (1892-1895) se ancla en los años inmediatamente anteriores al estallido de la denominada Guerra Necesaria (1895-1898), etapa vital de adoctrinamiento y organización de 
la revolución, que a su vez coincide con el período en que Martí dirige el periódico, hasta su muerte en batalla.

Palabras clave: Guerra de independencia cubana, españoles, prensa revolucionaria, prensa conservadora.

\title{
The press and separatist Spaniards at the dawn of Cuba's war for independence
}

\begin{abstract}
This article discusses the role of the press during the Cuban independence struggle, in relation to the participation of Spaniards in the fight for the emancipation of Cuba. The main source of this study is the newspaper Patria founded by José Martí, which we consider the main exponent of the revolutionary Cuban press in times of preparation for the anti-colonial war. The specific objective is to analyze the discourse that the medium directs particularly to the Hispanic community, observing the modes of interpellation and discursive arguments that it develops to convince the Spaniards to support the independence of Biggest Antilla and their separation from Spain. At the same time, there is an imaginary dialogue, a journalistic and ideological debate, between Patria (revolutionary press) and the official peninsular press (liberal-conservative), which, through contrary arguments, also disputed the participation of the Iberian community in the war in Cuba. The time frame selected (1892-1895) is anchored in the years immediately prior to the outbreak of the so-called Necessary War (1895-1898), a vital stage of indoctrination and organization of the revolution, which in turn coincides with the period in which Martí was the Director of the newspaper, until his death in battle.
\end{abstract}

Key words: Cuban war of independence, Spanish, revolutionary press, conservative press.

\section{Introducción: El PERIÓdico P ATRLA COMO EXPONENTE DE LA PRENSA REVOLUCIONARIA CUBANA Y SUS DESTINATARIOS HISPANOS}

A la hora de organizar la guerra de independencia de Cuba, ${ }^{1}$ el líder separatista y prócer cubano José Martí se valió de dos instrumentos

1 Nos referimos a la última guerra de independencia cubana en contra del Imperio Español, conocida como la Guerra Necesaria (1895-1898) y que fue la contienda definitiva en tanto 
fundamentales: el Partido Revolucionario Cubano (PRC) y el periódico Patria como su órgano representativo. Tanto la institución partidaria como su medio de prensa oficial fueron fundados y también dirigidos por Martí desde 1892 hasta su muerte en batalla en 1895, aunque ambos se mantendrían operando hasta 1898 , año en que concluye la contienda y se alcanza la independencia formal de la isla.

Nuestro objeto de estudio específico es el medio de prensa Patria, ${ }^{2}$ periódico al que venimos trabajando desde hace algunos años ${ }^{3}$ y al que consideramos —durante el período que aquí estudiamos 1892-1895- el principal exponente

logró, de una vez y para siempre, la completa separación de España (aunque aquí podrían hacerse distintas salvedades en función de la nueva dependencia que se generó con Estados Unidos a partir de su intervención en el conflicto, pero esto pertenece a otro tema). No obstante, es importante aclarar que esta guerra no fue la única ni la primera que emprendió el pueblo cubano por su libertad, sino que representa la etapa final de todo un proceso prolongado de luchas y resistencias que se extendió por décadas a lo largo de la segunda mitad del siglo xIX, siendo los antecedentes bélicos más importantes la Guerra Grande (1868-1878) y la Guerra Chiquita (1879-1880).

2 Respecto al estado del arte sobre el periódico Patria, sorprende la escasez de trabajos sobre el medio, siendo tan voluminosa la bibliografía que trabaja la prensa en relación con la guerra de cuba (se citarán las referencias pertinentes más adelante). En cuanto a la producción de libros, al respecto sólo hallamos dos obras compilatorias que agrupan artículos de Patria según temáticas específicas - lo que representa un enorme aporte a la hora de estudiar los tópicos en cuestión porque se dispone del material seleccionado y ordenado- pero éstas no constituyen ediciones críticas ni se dedican al análisis de los textos, aunque sí cuentan con un prólogo introductorio: tal es el caso de la recopilación de Ripoll Carlos, Patria: el periódico de José Martí: registro general de 1892-1895, la de Salvador Bueno, titulada José Martí y el periódico Patria, y la de Edgardo Meléndez, Puerto Rico en Patria, que recoge los principales escritos del periódico sobre el país boricua.

Por otro lado, es más común encontrar referencias a Patria en trabajos que no son específicos del medio, sino que mencionan a Patria como ejemplo de la labor periodística general de José Martí, como es el caso de Villalobos Jiménez "La misión del periodismo en José Martí” o Toledo Sande, “José Martí, el don de la propaganda”. A su vez, existen ciertos artículos o ensayos muy breves que reseñan o comentan el periódico y que, aunque no son trabajos académicos, sí fueron realizados por especialistas sobre el tema, normalmente con motivo de acontecimientos especiales, como los festejos de su aniversario y la celebración del Día de la Prensa en Cuba. Por mencionar sólo algunos, podemos citar: Julio García Luis, "Volver a leer a Patria", donde se utiliza la fecha del centenario de la fundación de Patria como disparador para hacer un análisis del porvenir del periodismo cubano contemporáneo; Jesús Dueñas Becerra, "José Martí, el periódico Patria y el periodismo revolucionario"; Sanabia Diony; "Patria, periódico de José Martí desde EUA", Carmen Suárez León, "Comentarios al periódico Patria"; Adalys Pérez Suárez "Patria, emblema del periodismo cubano", la mayoría constituyen notas publicadas en plataformas web cubanas en alusión al 14 de marzo.

3 Para esta investigación se han consultado todos los ejemplares del periódico desde 1892 a 1895 en su versión facsimilar, disponible en la Biblioteca del Centro de Estudios Martianos (CEM), La Habana, Cuba, institución que actualmente se encuentra en proceso de digitalización de la colección completa. 
representativo de la prensa revolucionaria cubana (a pesar de ser producido y editado en tierra extranjera, como la mayoría de los medios opositores al gobierno colonial que sufrían la persecución y censura dentro de la isla). Su destacado protagonismo se debe indudablemente al hecho de materializar la pluma de Martí, quien efectivamente organizó y lideró el estallido de la revolución separatista. A continuación, introduciremos sólo algunos datos elementales del periódico, ya que éste ha sido objeto de otros trabajos específicos que hemos realizado previamente y se encuentran referenciados en la bibliografía y disponibles para su consulta.

Fue editado desde Nueva York por Martí y otros emigrados antillanos, ${ }^{4}$ en su mayoría exiliados políticos, que habían vivenciado en carne propia el autoritarismo y la opresión del gobierno colonial español. Juntos se dedicaron a la misión de orientar el potencial del periodismo hacia la construcción de un movimiento nacionalista cubano que se convenciera de la necesidad histórica de la guerra de emancipación. Producido con mucho esfuerzo y poco presupuesto, salía a luz cada sábado y aunque su campo inmediato de circulación estaba demarcado por las localidades en Estados Unidos. donde existían importantes comunidades cubanas, ${ }^{5}$ su equipo editorial hacía titánicos esfuerzos y desarrollaba hábiles estrategias para que ingresara y circulara clandestinamente también dentro de la isla de Cuba.

El propósito explícito y asumido por el periódico, declarado como misión fundacional, era contribuir a la revolución independentista de Cuba, y ciertamente desempeñó un rol de sumo grado en el proceso previo de adoctrinamiento y organización que se requería para efectuar la guerra. ${ }^{6}$ Sus páginas se dedicaron a concientizar, ideologizar y poner en situación de contacto y comunicación a quienes integrarían el movimiento separatista y se levantarían en armas contra el sistema de dominación español. Además, informaba a su público no sólo sobre los avatares de la política, sino también sobre las cuestiones relacionadas con la organización interna del PRC, avisaba de las reuniones y mítines en los clubes políticos y servía como canal para recaudar fondos y reorientarlos a la causa de la independencia.

4 Aunque José Martí era el Director y Jefe de redacción del periódico, autor de la mayoría de los artículos editoriales, otras grandes personalidades integraron el equipo de Patria: se destacan por su presencia sistemática Sotero Figueroa, Gonzalo de Quesada y Aróstegui, Fernando Figueredo Socarrás, Benjamín Guerra, entre otros.

5 Por ejemplo, además de Nueva York, Tampa, Cayo Hueso, Atlanta, Brooklyn, Jacksonville, Thomasville, Chicago, Philadelphia, Ocala, New Orleans, entre otras.

$6 \quad$ Esta hipótesis fue desarrollada y defendida en investigaciones previas específicas sobre el periódico Patria y que tomaron cuerpo en la tesina de licenciatura titulada El periódico Patria como mediación revolucionaria en el proceso de Independencia en Cuba y en la tesis de maestría José Martí y el periodismo revolucionario: los inicios del periódico Patria (1892-1893), ambas de mi autoría y citadas en la bibliografía final. 
A su vez, Patria desarrolló un discurso sumamente cauto en no excluir ni alejar de la causa emancipatoria a ningún grupo social en particular. Por el contrario, su equipo editorial era consciente de que se requería sembrar una unidad lo más amplia posible para poder triunfar en la campaña. En consecuencia, así como se dirigió de manera singular a los distintos colectivos y a través de discursos diversos que tuvieran en cuenta las particularidades de los diferentes sectores de la sociedad (propietarios / trabajadores urbanos / mujeres / población afrocubana), Patria también elaboró un mensaje específico para los españoles, convirtiéndolos en un grupo concreto y delimitado entre sus interlocutores.

Aunque en primera instancia pueda parecer extraño que los españoles resultasen destinatarios del llamamiento a la guerra contra España, esto respondió a diversos motivos. En primer lugar, los peninsulares representaban en la época un contingente poblacional importante dentro de $\mathrm{Cuba} ;{ }^{7}$ no obstante, no era sólo en términos cuantitativos ni estratégicos que pensaba Martí. Por el contrario, su intención de atraerlos al movimiento respondía también a una profunda convicción ideológica y un sentimiento de fraternidad, que lo llevara a asegurarles un lugar digno en la futura y anhelada república. Veremos en este sentido, cómo se procura distinguir a los españoles, en tanto individuos, del gobierno que se cuestiona.

Por supuesto que la persuasión o atracción a la causa independentista de este grupo singular estaría surcada de obstáculos y desafíos, dadas las presiones a las que se veían sometidos los españoles por la construcción de un deber ser, un fuerte mandato de carácter ético que exigía la defensa de la propia patria. Éstas eran las ideas dominantes en los discursos emitidos por varios medios peninsulares - $\mathrm{O}$ en Ultramar por sus voces representantes - y que se pusieron en circulación con gran eficacia, logrando su apropiación por gran parte de la población.

No obstante lo anterior, muchos españoles apoyaron la causa separatista, y entre ellos, varios incluso lucharon en batalla contra las fuerzas de su patria natal. Además, no sólo peninsulares que se encontraban viviendo en Cuba se sintieron atraídos por el PRC y desarrollaron un importante rol en la contienda. También españoles que ni siquiera vivían en la isla, sino junto a la emigración antillana en Norteamérica e, incluso, varios de quienes viajarían a Cuba desde

7 En cuba vivían de forma permanente unos 129.240 españoles, según la contabilización del último censo del siglo, realizado en 1899 por el gobierno norteamericano en la isla. Esta cifra que representaba el $75 \%$ de los extranjeros en Cuba, es posterior al desenlace de la guerra por lo que incluye solo a los españoles que habían decidido quedarse a pesar de los convulsivos hechos. Alonso Valdés, "La inmigración española en Cuba como fuerza de trabajo: 18001933", pp. 8-9; Tornero, "Desigualdad y racismo. Demografía y sociedad en Cuba a fines de la época colonial", p. 27. 
España específicamente para luchar en la guerra se cambiarían de bando y unirían a las fuerzas revolucionarias.

Las causas y motivaciones en juego a la hora de considerar esta última opción por parte de los españoles fueron hondamente complejas y tan diversas como lo era la propia comunidad hispana en su interior. Lógicamente, a pesar de compartir la nacionalidad debido al lugar de nacimiento, como grupo poblacional en su conjunto estaba en las antípodas de ser homogéneo, sino que se diferenciaba en función de criterios múltiples, sociales, culturales y espaciales. Así, veremos cómo a partir de sus diversas condiciones, algunos se sintieron interpelados por la ideología del partido revolucionario y en cambio, otros repelidos por las arbitrariedades o condiciones materiales del ejército oficial; unos se unieron desde el principio del conflicto y por férrea convicción, mientras que otros tomaron la decisión de mudar de bando ya avanzada la contienda.

A pesar de la gran variabilidad de situaciones que ocurrieron, en consonancia con la heterogeneidad intrínseca de la población española, efectivamente un considerable número de hispanos apoyó la lucha independentista. De este hecho objetivo y empírico parte el presente trabajo, y es en función de este tópico que nos interesa acudir a la prensa: nos proponemos enlazar ambos temas al contemplar los esfuerzos que a través del periodismo se realizaron por convencer y atraer específicamente a la comunidad hispana hacia la causa de la guerra de Cuba. Nos interesa analizar tanto el engranaje ideológico como las estrategias de convencimiento que Patria pone en acción para interpelar al público hispano, en contraposición al mensaje hegemónico que imponían los medios ibéricos. La tesis subyacente a esta idea comprende al periódico no sólo como una fuente de tiempos pretéritos, sino como un agente y actor político de su época, que busca ejercer influencias en la opinión pública para impactar posteriormente en la arena política.

En consecuencia, dedicaremos el segundo apartado a explicar y clarificar algunas nociones en torno a la colectividad española: veremos qué grupos de españoles fueron los más receptivos a las ideas revolucionarias (teniendo en cuenta distintos factores como su situación socioeconómica y su procedencia geográfica) y contemplaremos algunos de los posibles móviles que experimentaron la hora de combatir por la separación cubana de España. También incorporaremos ciertos datos cuantitativos que nos permiten hacernos una idea más precisa sobre las cifras y características de su participación en la guerra.

En el apartado siguiente nos adentraremos en el universo de la prensa. Focalizaremos en el discurso suasorio enunciado por Patria destinado a los españoles, observando los argumentos que sostenían sus mensajes de adoctrinamiento y persuasión. En paralelo, compararemos estos últimos con 
los enunciados por la prensa peninsular que se alineaba con el discurso oficial. Por supuesto que la prensa española no se agotaba en los periódicos liberalconservadores adeptos al gobierno monárquico, pero es este tipo de prensa la que permite generar un juego más rico de oposiciones, y ver así cómo los españoles fueron una comunidad en disputa por ambos bandos, quienes compitieron por atraer su participación a su favor.

Con el desarrollo de estos tópicos nos proponemos comenzar a cubrir un vacío historiográfico prominente en distintos sentidos, ya que ambos temas resultan muy poco explorados. En primer lugar, la participación de españoles a favor de la emancipación de Cuba es un tema poco trabajado y, aunque en su época ha sido intencional y políticamente ocultada, aún hoy en día permanecen postergados los estudios al respecto. Por otro lado, aunque mucho se ha escrito sobre el rol de los medios en tal coyuntura, la atención se centró en la guerra mediática España vs. Estados Unidos y en el último año de la contienda (1898), postergando el tratamiento de la prensa antillana radicalizada. En cuanto al recorte temporal, hay una gran carencia sobre el rol del periodismo en la etapa inmediatamente previa al desenlace de la guerra, período vital para el adoctrinamiento de los grupos que luego se dispondrían a efectuar en armas la revolución/contrarrevolución.

\section{LOS ESPAÑOLES FRENTE A LA OPCIÓN SEPARATISTA}

\section{Posibles móviles y razones para su adhesión revolucionaria}

Entre las múltiples causas que han podido llevar a los españoles a defender la independencia cubana encontramos razones muy disímiles, las cuales dependen de los diferentes grupos sociales, situaciones y experiencias de vida personales. En este artículo focalizaremos especialmente en los españoles que decidieron tomar un rol activo en la lucha separatista y participar directamente en la guerra a través de la toma de armas, lo que incumbe mayormente a los que ya residían en Cuba o viajaron a la isla en las filas del ejército oficial y luego desertaron. Por el contrario, no contemplamos, por el momento, a peninsulares que desde el territorio español manifestaron su apoyo teórico a la distancia, a través de distintos medios.

Antes de analizar los discursos ideológicos/periodísticos es necesario aclarar que los motivos que pudieron llevar a los españoles a elegir la opción separatista no tuvieron única ni exclusivamente que ver con la empatía o apropiación de los ideales que propagaba el movimiento revolucionario. Al contrario, a veces resultaron más efectivos los factores de expulsión que los de atracción, siendo la necesidad de escapar de un sistema percibido como opresivo lo que hacía que muchos hispanos decidieran enfrentarlo. Para otros, en lugar de motivaciones ideológicas o desacuerdos morales con el 
colonialismo en sí, fue la práctica cotidiana y la experiencia de vida día a día en Cuba, como los lazos afectivos allí establecidos, o el desarrollo de un negocio familiar en la isla, lo que hizo añorar una mayor libertad y prosperidad para la Gran Antilla. Para muchos, fue una combinación de varios factores la que determinó la decisión.

Es importante tener en cuenta que la identidad de los españoles no se conformaba únicamente sobre el principio aislado de su nacionalidad, sino que se solapaba o yuxtaponía sobre otras facetas o esferas identitarias. Así, había españoles terratenientes, comerciantes, campesinos, obreros urbanos, que vivían en unas y otras regiones tanto de Cuba como de España, cada una con sus condiciones materiales y tradiciones culturales, e incluso había emigrados en Estados Unidos. Políticamente también los había desde conservadores a anarquistas.

En consecuencia, aunque en este estudio abstraeremos la parte del discurso periodístico que apela especialmente al aspecto nacional de su identidad, debemos ser conscientes de que siempre se conjugan a su vez otros condicionantes y sentidos de pertenencias. Así, por ejemplo, para algunos pesaría más su condición de obreros explotados que su nacionalidad española, y al revés, muchos criollos, a pesar de ser cubanos, se opondrían a la independencia de Cuba en función de intereses materiales y beneficios gubernamentales. Por lo tanto, cada mensaje dirigido a los españoles se articulaba y complementaba con otros discursos que apelaban a diversas condiciones sociales e identidades heterogéneas, en correlación con la diversidad poblacional hispana.

La inmigración peninsular a Cuba durante el siglo XIX, además de muy significativa en cuanto a sus dimensiones, fue también sumamente variada: el gobierno español no sólo había incentivado el arribo a la isla de militares y altos funcionarios políticos o eclesiásticos, sino también de todo tipo de civiles y trabajadores sujetos a contrata. Si bien este flujo había sido constante a lo largo del siglo, vivió un importante aumento en la década de 1850, y sobre todo a partir de 1870, cuando comienza una nueva oleada inmigratoria en masa que tendría fuertes efectos transformadores en la estructura social cubana. Este proceso fue posible gracias a distintas medidas jurídicas que el gobierno impulsó a partir de 1853 para facilitar el traslado de los españoles al exterior.

A su vez, dicho crecimiento inmigratorio estuvo motivado, tanto por la pujante economía insular - sobre todo por la gran alza de las exportaciones del azúcar y el tabaco - como por los factores de expulsión que actuaron al interior de la península, relacionados con la presión demográfica y las dificultades económicas. ${ }^{8}$ Esta combinación de elementos dio como resultado

8 El crecimiento poblacional en la península, sumado al último proceso de desamortización llevado a cabo por el ministro de Hacienda Pascual Madoz en 1855 que privatizó, además de las propiedades de la iglesia, las tierras comunales de los ayuntamientos, empobreció a 
una emigración sumamente heterogénea desde lo social y una variabilidad de móviles que iban desde el enriquecimiento a la supervivencia. Es decir, hizo que al mismo tiempo decidieran trasladarse a la isla desde comerciantes atraídos por incentivos mercantiles y financieros, buscando beneficiarse de grandes privilegios monopólicos, a peones y trabajadores urbanos muy pauperizados en búsqueda de una calidad de vida digna.

Sin embargo, existía una notable diferencia entre el panorama que se pretendía y anhelaba desde la lejanía, el desconocimiento y las promesas oficiales, y el que realmente se encontraban los migrantes al desembarcar. Los autores Blanco Rodríguez y Alonso Valdés, ${ }^{9}$ ponen de manifiesto las condiciones muchas veces negativas en las que se hallaron los trabajadores españoles en la isla de Cuba y, ante esto, el sentimiento de decepción, injusticia o indignación que generara en este colectivo una gran inconformidad con la actuación de la administración peninsular.

La política de inmigración a la isla que impulsó el gobierno colonial no fue acompañada de medidas que asegurasen un traslado propicio y seguro para los españoles que viajaban ni contención institucional o posibilidades laborales aseguradas al arribar. Por el contrario, la explotación no sólo era ardua, sino que usualmente contaba con la pasividad o incluso complicidad de los funcionarios metropolitanos. El alto costo del pasaje transatlántico hacía que muchos españoles se endeudaran o viajaran después de firmar contratos muy severos, debiendo quedarse años resistiendo férreas condiciones hasta que cumpliesen el plazo pactado, lo que representaba una situación de semiesclavitud temporal, ${ }^{10}$ siendo muy común las deserciones y fugas. A la vez, si estas circunstancias tenían lugar entre quienes inmigraban legalmente, peor era para quienes lo hacían de forma ilegal, escapando del servicio militar, deudas o impuestos.

Estas afirmaciones ayudan a romper el tan difundido mito respecto a que la mayoría de los españoles viajaban a hacer la América, es decir, engendrar una fortuna en pocos años y volver triunfantes a la península; aunque sin dudas

miles de campesinos, muchos de los cuales optaron por viajar a Cuba con la esperanza de encontrar un trabajo que les asegurara el sustento. Entre los que migraron se destacaron tradicionalmente los canarios y catalanes, y en las últimas décadas los procedentes del norte de la península, principalmente asturianos y gallegos. Casanovas Codina, ; O pan, o plomo! Los trabajadores urbanos y el colonialismo español en Cuba, 1850-1898, pp. 46-57 y 238309.

9 Si bien el objeto específico de estos autores es la participación de los españoles de Castilla en la guerra de Cuba (su libro se titula La Presencia castellana en el ejército libertador cubano) en su estudio encontramos abundantes referencias a la situación de los españoles en general, por lo que a lo largo del texto tomaremos varios de sus aportes.

10 Blanco Rodríguez y Alonso Valdés, Presencia castellana en el "ejército libertador cubano" (1895-1898), pp. 57-64 у p. 157. 
este fue el sueño de muchos y ciertamente fue posible para varios. ${ }^{11}$ Pero no se puede menospreciar el significativo número de inmigrantes que debieron enfrentarse a un panorama menos esperanzador del que aguardaban, incluso a veces igual de hostil que aquel del que escapaban. Esta situación abonó en el interior de la isla, entre distintos grupos de españoles, una especie de sentimiento de abandono y malestar con el gobierno, de gran fertilidad para las ideas revolucionarias.

A su vez, en dicho contexto, un gran número de inmigrantes hispanos probaron diferentes estrategias para aliviar su situación. Mientras algunos escaparon de las plantaciones a las que por contrata estaban obligados, buscando mejores oportunidades en la ciudad, sobre todo en La Habana, otros siguieron una ruta ya habitual para los cubanos, que consistía en buscar superiores condiciones de vida y posibilidades laborales en Estados Unidos. La mayoría de los que optaron por esta opción, se instalaron al sur del país, especialmente en La Florida, por la cercanía geográfica y la floreciente industria que allí existía en torno al tabaco importado de la isla. En este marco, varios entraron en contacto con los grupos de trabajadores cubanos emigrados y concretamente con las labores de organización e ideologización que allí llevaba a cabo el PRC, empatizando con las ideas difundidas por José Martí, e incluso sintiéndose interpelados por su proyecto.

Por otro lado, muchos españoles radicados en Cuba, independientemente de sus condiciones laborales, habían echado raíces al estar asentados en la isla un tiempo considerable, y habían formado allí familia, gestado vínculos personales, o establecido sus proyectos económicos. Esto permitió que

11 Un tipo de documentación sumamente rica, además de los registros fiscales o económicos, para estudiar el fenómeno de quienes lograron enriquecerse, pero también del conjunto de expectativas y deseos que se proyectaban en torno al sueño de hacer la América, lo constituyen las fuentes epistolarias. Contamos con diferentes compilaciones de cartas privadas de emigrantes españoles que escribían desde Cuba a parientes y antiguos vecinos de la península, que reflejan sus visiones sobre la realidad política y económica, así como sus anhelos personales de progreso social y material. El libro de María Dolores Pérez Murillo Cartas de emigrantes escritas desde Cuba. Estudio de las mentalidades y valores en el siglo $X I X$ reúne un conjunto de cartas-reclamo de españoles que habían alcanzado en Cuba una buena posición económica y escriben para ofrecer a algún familiar o paisano de su localidad el viaje a la isla. Si bien se reúnen testimonios que corresponden a la primera mitad del siglo XIX, etapa previa a nuestro período de estudio, da cuenta, desde una perspectiva íntima y humana, de la existencia de un gran grupo de peninsulares que lograron una situación de bienestar y se propusieron ayudar $u$ ofrecer a sus allegados mejores posibilidades de las que gozaban en el viejo continente. Por otra parte, el libro de María Luisa Martínez de Salinas Alonso Noticias de Cuba. Cartas de emigrantes vallisoletanos en la segunda mitad del siglo $X I X$, reúne las cartas exclusivas de su archivo familiar destinadas a uno de sus antepasados, testimonio también de alguien que pudo conquistar una relativa fortuna en América, aunque la mayor riqueza de estas tiene que ver con la opinión política de primera mano que contienen sobre los acontecimientos de finales del siglo XIX. 
desarrollasen un sentido de pertenencia identitaria, que muchas veces derivó en un incipiente sentimiento nacionalista cubano. Consideramos que este grupo, junto al antes mencionado, fueron los más propensos a absorber el ideario martiano que propagó el PRC a favor de la fundación en Cuba de una república libre y democrática.

Otro aspecto a destacar, que también influyó en la receptividad con que muchos peninsulares acogieron el llamado separatista como una opción viable, tuvo que ver con la manera en que vivenciaron la experiencia militar dentro de las fuerzas oficiales ya iniciada la guerra. Las distintas instancias del proceso - es decir, tanto el inicio del reclutamiento como el servicio activo una vez dentro del ejército - en general fueron percibidas como abusivas, a veces hasta deshumanizantes, y sobre todo sumamente injustas. Esto originó una gran diversidad de estrategias puestas en práctica para oponerse a tal sistema y escapar de sus imposiciones, entre las cuales se encontró el cambio al bando armado contrario.

El sistema de alistamiento al que se vieron sometidos los españoles ha sido descrito por distintos autores como profundamente injusto, dado que éste recaía sobre los más débiles de la pirámide socioeconómica. Si bien la prestación militar era obligatoria y se imponía sobre una quinta parte de los jóvenes de cada distrito, que eran seleccionados a través de un sorteo, a partir de una ley en 1896 se permitió redimir la obligación mediante un elevado pago. ${ }^{12}$ La suma exigida quedaba fuera del alcance de la mayoría de la población, por lo que sólo accedían a tal privilegio las capas sociales de ingresos o capitales más elevados. Dicha discriminación no sólo se desplegaba en dirección vertical por la pirámide social, sino también en sentido geográfico, ya que las diferencias de posibilidades se acentuaban notoriamente entre las zonas más ricas y las más pobres del mapa español.

A las desigualdades de la etapa inicial se sumaba en la instancia posterior, la dureza del servicio militar, su larga duración, las posibilidades de perder el oficio tras períodos de prestación demasiado extensos, y las condiciones degradantes durante el transcurso de la guerra. Una vez iniciada la contienda, los soldados fueron trasladados a Cuba hacinados y en pésimas condiciones, empeorando aún más la situación al llegar a la isla. Las tropas estaban hambrientas y anémicas, ya que las subsistencias eran totalmente deficientes. La asistencia sanitaria destacaba por su pauperismo y los hospitales carecían de materiales y medicamentos imprescindibles. Así, las primeras causas de mortandad fueron el hambre y las enfermedades (sobre todo la fiebre amarilla), seguidas por el agotamiento, la inadecuada vestimenta, y sólo por último, las

12 El pago era de 1500 pesetas si el servicio debía prestarse en el interior de la península o 2000 pesetas si el destino era en Ultramar, Blanco Rodríguez y Alonso Valdés. Presencia castellana en el "ejército libertador cubano" (1895-1898), pp. 57-64. 
causas estrictamente militares. En los primeros dos años de guerra apenas el $4 \%$ de las muertes fueron bajas en batalla o a causa de heridas sufridas en las mismas.

La pesadilla continuaría para los sobrevivientes, ya que los traslados de vuelta a la península repetían las condiciones deplorables, muchos morían en el trayecto, otros al poco tiempo de desembarcar, y los que permanecían vivos se veían en medio de la miseria y abandono por parte de la administración. El Estado no se responsabilizaría adecuadamente de la reinserción de los excombatientes en sociedad ni del tratamiento de las enfermedades contraídas en ultramar, tampoco proveería la asistencia necesaria para su recuperación económica y social.

Ante estas situaciones de padecimiento se desplegaron una variedad de estrategias como vías de escape. Algunas fueron legales, como la renuncia de los militares profesionales al servicio activo, ${ }^{13} \mathrm{o}$ la redención en metálico que, como vimos, libró a los jóvenes más pudientes del servicio militar. Otras, se ubicaron en una especie de estadio intermedio, ya que, aunque se les concedió una apariencia legal, en gran parte de los casos eran resultado de manejos discrecionales, sobornos, maniobras cacicales, o favores personales, como las declaraciones de no aptos por impedimentos físicos, o exceptuados por razones sociales. ${ }^{14}$ Por último, quienes no tenían dinero ni contactos, acudían a conductas totalmente excluidas de la legalidad y punibles, como la huida o la deserción. ${ }^{15}$

En total, los prófugos y exceptuados representaron en torno a una cuarta parte de los alistados, llegando en 1896 al $27.87 \%$, y si a este número sumamos los no aptos, da un balance de que sólo la mitad de los alistados ejercieron realmente como soldados. ${ }^{16}$ En este contexto, donde muchos españoles decidieron desertar del ejército peninsular agobiados por circunstancias infrahumanas, varios optaron por buscar mejores expectativas en el ejército contrario, a lo que podían agregarse otras motivaciones o ideas que reafirmaban

13 En sólo unos pocos meses, desde el inicio de la guerra hasta fines de 1895, pidieron el retiro 671 jefes y oficiales del ejército.

14 El porcentaje de "no aptos" alcanzó el $22.82 \%$ en 1896, aunque en los años siguientes decreció ligeramente porque el control pasó a manos militares y se hizo más estricto, en cambio, aumentó entonces como contraparte el número de "exceptuados" que para 1896 representaba un $24.31 \%$. (Pérez Ledesma, 1998, p. 114).

15 El número de prófugos que no acudieron al alistamiento fueron sobre todo elevados en las zonas en el norte y sudeste, como, por ejemplo, en Galicia llegó a representar un 13.26\% del contingente, debido a que en las zonas marítimas o fronterizas se hallaban mayores facilidades para la huida. Pérez Ledesma, "La sociedad española, la guerra y la derrota", p. 114 .

16 Blanco Rodríguez y Alonso Valdés, Presencia castellana en el "ejército libertador cubano" (1895-1898), pp. 57-64 y p.157; Pérez Ledesma, "La sociedad española, la guerra y la derrota", pp. 91-150. 
esta opción. Por lo tanto, la adhesión de algunos a la causa separatista no se originaría por una convicción férrea y una determinación desde el inicio, sino por una toma de decisiones posterior, ante las nuevas experiencias y perspectivas surgidas durante la guerra.

Todas estas posibles situaciones mencionadas, nos llevan a horadar el supuesto clima de fervor patriótico de los españoles en torno a la guerra de Cuba, que, si bien existió, tuvo sus zonas de sombras y tensiones. Hasta ahora, podemos afirmar que existieron y convivieron una gran variedad de razones y acciones que coincidieron en interponer una resistencia al conjunto de ideas y actitudes que el sistema colonial exigía. Y a su vez, vimos que en distintas ocasiones esta oposición manifestada por los peninsulares que rechazaron los mandatos del gobierno monárquico se combinó con la decisión de formar parte del movimiento revolucionario.

\section{Características de la participación española en la lucha independentista cubana}

En este apartado nos centraremos especialmente en la participación hispana de carácter militar, es decir, en aquellos españoles que ejercieron un rol activo en la guerra y tomaron las armas en el marco del ejército mambí, dado que de ésta tenemos pruebas fehacientes y estadísticas numéricas al respecto (a las que referiremos luego). No obstante, no debemos olvidar que existieron muchas otras formas de apoyo y adhesión a la causa separatista además del involucramiento directo en la lucha armada, aunque éstas sean más difíciles de estudiar y, sobre todo, de cuantificar.

Si observamos la composición de las fuerzas mambíes, vemos que, aunque la mayoría de sus integrantes fueron cubanos, también hubo de otras nacionalidades, entre los que predominaron españoles, procedentes de todas las regiones de España. ${ }^{17}$ Para estas aseveraciones, sustentadas en cifras objetivas, contamos con los registros de estadísticas oficiales, además del testimonio que la prensa ha dado. A pesar de que los medios peninsulares intentaron ocultar esta situación y restarle importancia, hemos hallado referencias al respecto que reflejan preocupación desde el primer momento. Por ejemplo, el diario conservador madrileño, La correspondencia de España, a sólo dos meses de

17 Los españoles que se licenciaron del ELC pertenecieron a las diferentes Comunidades Autónomas en la siguiente proporción: canarios $41.6 \%$, andaluces $14.1 \%$, gallegos $8.8 \%$, asturianos $4.9 \%$, catalanes $4.7 \%$, castellano-leoneses $4.6 \%$ y valencianos $4.3 \%$, constituyendo estos los grupos de mayor representación. Estas estadísticas fueron obtenidas de: Blanco Rodríguez y Alonso Valdés. Presencia castellana en el "ejército libertador cubano" (18951898), pp. 138-140. 
iniciada la contienda, afirma sobre uno de los batallones mambíes "entre las fuerzas de Guerra hay más de 50 peninsulares". ${ }^{18}$

A través de los periódicos hispanos no sólo podemos recoger algunos datos cuantitativos sobre el aporte de los españoles, sino también del estatus o jerarquía que éstos ocupaban. Cuanto más alto era el rango desempeñado (algunos ocuparon las más altas posiciones militares, alcanzando varios al grado de General) más duros eran los castigos que reclamaban por la traición. Así, el periódico El Norte de Castilla ${ }^{19}$ exclama: "si el delito del separatismo es grave en cualquiera de los que lo profesan, lo es doblemente en españoles de la categoría de los detenidos en La Habana, y en tal sentido deberán ser castigados con la mayor severidad posible". ${ }^{20}$

En su conjunto, los españoles representaron el 2\% del total del ejército mambí, que según los datos aportados por el Mayor General Carlos Roloff, contó con 69718 miembros. ${ }^{21}$ Según las cifras oficiales, 1361 españoles fueron licenciados formalmente del ejército cubano (entre 1806 extranjeros, representando, por lo tanto, el 75.3\%). ${ }^{22}$ No obstante, también se deben tener en cuenta otras categorías que en los expedientes se nombran como rechazados o desestimados (es decir, que no se les retribuyó económicamente sus servicios), ${ }^{23}$

18 "Una interview", La Correspondencia de España. Diario universal de noticias, año XLVI, núm. 13589, Madrid, 21 de abril de 1895.

19 Este periódico, citado recurrentemente a lo largo del trabajo, es analizado en la obra mencionada de Blanco Rodríguez y Alonso Valdés, dado que fue uno de los medios más importantes e influentes de la región de Castilla, zona muy sensible a la cuestión cubana. Al fundamentar la elección de esta región para el análisis, los autores explican que la guerra de Cuba fue un tema de vital interés para esta comunidad a causa de dos razones principalmente. En primer lugar, por los importantes intereses económicos de los propietarios trigueros e industriales harineros castellanos en el mantenimiento del orden colonial, ya que veían favorecidas sus importaciones en la isla a través de una regulación proteccionista que los agraciaba con una rentabilidad asegurada. En segunda instancia, porque la contribución a la guerra se vio surcada por una gran desigualdad social y regional (ya que la pobreza en el interior de España privó a gran parte de las capas populares de la redención en metálico para librarse del servicio militar) y la contribución en hombres fue muy superior en las dos Castillas, Andalucía o Extremadura que en otro lugares como Cataluña o el País Vasco, pese a los grandes intereses en juego por parte de la burguesía de estas dos últimas regiones.

20 "Sin contemplación", El Norte de Castilla, Valladolid, 23 de julio de 1896, citado en Blanco Rodríguez y Alonso Valdés. Presencia castellana en el "ejército libertador cubano” (18951898), pp.78-104.

21 Contra 260000 miembros del ejército oficial, según Blanco Rodríguez y Alonso Valdés. Presencia castellana en el "ejército libertador cubano" (1895-1898), pp. 130-132.

22 Blanco Rodríguez y Alonso Valdés. Presencia castellana en el "ejército libertador cubano" (1895-1898), p. 136.

23 La denegación del pago por licenciamiento podía deberse a diferentes razones, como no demostrar las pruebas requeridas de la participación en el ejército, no haber desempeñado un rol activo, haberse incorporado demasiado tarde, o presentar la reclamación fuera de plazo, entre otras. También existieron quienes sin haberse involucrado intentaron beneficiarse con 
más aquellos que no se incluían en ninguna de las categorías anteriores al no haber presentado solicitud de licenciamiento (porque rechazaban obtener un pago por algo que hacían por amor a la causa). Esto elevaría la cifra presentada antes, que algunos autores como Moreno Fraginals y Moreno Masó estiman en 1640 españoles. ${ }^{24}$

Ya adelantamos que las vías de incorporación a las fuerzas rebeldes fueron diversas, y mientras algunos se identificaron con la lucha mambí desde el principio de la guerra - e incluso antes, durante la etapa de preparación-, otros lo harían en el trascurso de ésta. Es decir, unos entraron en contacto con los líderes independentistas (especialmente en territorio estadounidense) en un estadio temprano y participaron en las actividades previas de financiación y adoctrinamiento. Otros, que residían en Cuba, se unieron a la lucha tan pronto ésta alcanzaba sus propias comunidades. Por último, estuvieron quienes desertaron del ejército español o de otras fuerzas de seguridad, como los contingentes de voluntarios españoles e incluso la Guardia Civil. En este último caso fue muy común el cambio de bando al ejército cubano en el momento en que los grupos separatistas tomaban ciertas poblaciones o campamentos.

Pasando a una fase de análisis más cualitativa que cuantitativa, si examinamos la composición social de los españoles que se unieron a la causa de Martí, vemos que la mayoría de quienes declararon sus profesiones fueron campesinos, ${ }^{25}$ aunque también hubo obreros, pero en menor medida que los primeros. Ibarra Cuesta ${ }^{26}$ afirma que si se desconoce el número total de proletarios urbanos que participaron en el ejército mambí, menos se sabe cuántos de éstos eran de procedencia peninsular, pero asevera que muchos obreros españoles antepusieron su identidad nacional hispana por encima de su pertenencia social, con la excepción de los anarquistas, reacios a cualquier idea de patria.

Pese a la veracidad de las afirmaciones anteriores es posible realizar ciertas matizaciones. Casanovas Codina opta por destacar el importante rol que desempeñó el movimiento obrero cubano en la guerra de independencia, el cual era, según el autor, mayoritariamente anarquista ${ }^{27}$ (y en buena parte debido

los réditos económicos que suponía. Blanco Rodríguez y Alonso Valdés. Presencia castellana en el "ejército libertador cubano" (1895-1898), p. 157.

24 Moreno Fraginals y Moreno Maso, Guerra, migración y muerte (el ejército español en Cuba como vía migratoria).

25 Del total de españoles que explicitaron su profesión (1 177, constituyendo el $85.4 \%$ del total), el $70.4 \%$ se engloba dentro de la categoría de campesino ( 832 personas). Blanco Rodríguez y Alonso Valdés. Presencia castellana en el "ejército libertador cubano" (1895-1898), p.148.

26 Ibarra Cuesta, "La guerra del 95: ¿la guerra de la voluntad y del ideal o de la necesidad y de la pobreza?", pp. 451-470.

27 Casanovas Codina afirma que, antes de la década de 1880, la mayoría de los líderes obreros en Cuba eran reformistas republicanos que aceptaban la soberanía española, pero con 
a la influencia de los emigrantes españoles). A pesar de que se desconozca la magnitud exacta de su aporte y aunque éste no se tradujera expresamente en un alto número de combatientes, contribuyó de otras maneras de igual importancia. Según el autor, el hecho de que la mayoría de los soldados mambíes no fueran artesanos urbanos u obreros industriales, sino campesinos, no significa que aportaran menos a la causa; por el contrario, además de proporcionar algunos mandos militares destacables, su papel principal fue el de recaudar fondos, facilitar información, fabricar material de guerra y canalizar suministros al ejército libertador. ${ }^{28}$

Además, si bien el movimiento obrero en Cuba era, como dijimos, preponderantemente anarquista, ${ }^{29} \mathrm{su}$ lema anti-nacionalista paradójicamente tuvo un efecto positivo para la causa cubana, sobre todo en los peninsulares. La propaganda ideológica entre las clases populares a favor de la solidaridad internacional y en contra de la idea de patria, hizo que muchos españoles distinguieran entre un patriotismo que se identificaba con un estado colonial y opresor, de otro que luchaba por la libertad de su pueblo. Así, los anarquistas españoles en Cuba se tornaron mucho más críticos con las soflamas de carácter nacionalista que les exigían luchar por el honor — reproduciendo los términos del discurso oficial, que tan ajenos resultaban al universo anarquista- de un régimen al que condenaban. Desarraigados de la idea de patria en general, pero especialmente de la suya propia, supieron reconocer la justicia de la lucha cubana. ${ }^{30}$

En cuanto a su procedencia geográfica, la mayoría de los españoles que combatieron a favor de la revolución independentista fueron: canarios en un

posterioridad a dicha década, el anarquismo logró convertirse en la ideología preeminente dentro del obrerismo cubano. Casanovas Codina, "Movimiento obrero y lucha anticolonial en Cuba después de la abolición de la esclavitud", pp. 23-41.

Casanovas Codina, ;O pan, o plomo! Los trabajadores urbanos y el colonialismo español en Cuba, 1850-1898, pp. 238-309.

En Cuba - a diferencia de lo que ocurría en otros lugares y debido en parte al autoritarismo colonial y a la separación física y cultural entre los trabajadores urbanos y rurales que legó la esclavitud - el anarquismo tuvo un mayor arraigo en la ciudad, entre los trabajadores urbanos que integraban el movimiento obrero, que en el campo, donde usualmente solían resultar más atractivas las ideas anarco-colectivistas. Casanovas Codina, ;O pan, o plomo! Los trabajadores urbanos y el colonialismo español en Cuba, 1850-1898, pp. 238-309.

Por otra parte, en lo que refiere a los anarquistas españoles que se mantuvieron del otro lado del Atlántico, en tierras hispanas, éstos en conjunto se opusieron mediante su discurso al desarrollo de una guerra considerada burguesa y colonial. A su vez, algunos sectores además se manifestaron resueltamente a favor de la independencia de Cuba. No obstante, el anarquismo que se mantuvo dentro de la península no pudo en general accionar demasiado como movimiento político ni oponer una férrea resistencia más allá de declaraciones verbales, dada la persecución sobre el grupo y las leyes antiterroristas que buscaban ejercer un control especial sobre su agrupación. 
sobresaliente lugar (con una proporción de más del 41\%), seguidos de andaluces y gallegos, que constituían a su vez los grupos poblacionales mayoritarios de la emigración española en Cuba. No sucedió igual con los asturianos, por ejemplo, que, aunque también eran de los contingentes peninsulares más numerosos en la isla, superados sólo por los oriundos de las Islas Canarias, su participación en el ejército mambí no fue tan acusada, estimada sólo en un $4.9 \%$, destacándose, en cambio, su rol en las fuerzas oficiales (donde sí alcanzaron el $40 \%){ }^{31}$

Para entender la aportación tan desmedida y significativa de canarios a la revolución resulta útil considerar ciertas cuestiones particulares. La presencia canaria en Cuba además de muy numerosa era muy antigua: se remontaba a los primeros viajes de Colón a las Antillas, ya que, según la autora Medina Hernández, muchas veces "Canarias era la puerta de salida de Europa y Cuba la de entrada a las Américas". ${ }^{32}$ La cultura cubana tenía en sus cimientos muchos elementos de origen canario, sobre todo en el ámbito rural, ya que el grueso de la emigración había sido mano de obra principalmente agrícola, que partió en búsqueda de una mejor vida y lógicamente llevó consigo su idiosincrasia.

Ante lo dicho, destacan dos elementos para tener en cuenta. Las íntimas y antiguas relaciones humanas $\mathrm{y}$, sobre todo, los lazos económicos entre ambas islas, destacando la fragilidad y dependencia canaria de Cuba, ${ }^{33}$ inducirían,

31 Erice Sebares en su trabajo "Los asturianos ante la guerra de Cuba (1895-1898)", pp. 147-164, expone que al momento de iniciarse el conflicto bélico en 1895 vivían en Cuba probablemente unos 50.000 asturianos, cantidad únicamente superada por la colectividad canaria y mayor a la de gallegos. El autor destaca dos elementos propios de la comunidad asturiana que seguramente han incidido en que este grupo se volcara en tan alta proporción a la defensa de la integridad española: un paternalismo jerárquico y un ferviente patriotismo español. Los asturianos reprodujeron de la península una estructura social y un tejido asociativo marcado por una fuerte estratificación y un gran respeto a las jerarquías y autoridades. Las relaciones laborales se impregnaban de un "paternalismo protector de las clases adineradas y la deferencia respetuosa de los trabajadores y los sectores más modestos hacia sus patronos y superiores" (p. 152) (sobre todo en el sector comercial, donde la promoción social dependía de los vínculos familiares o de peonaje, y menos en el sector tabacalero, más propicio a los conflictos obreros-patronales). Por otro lado, el encuadramiento en los Cuerpos de Voluntarios era prácticamente un mandato social, ya que la mayoría de los notables y patronos asturianos militaban en la Unión Constitucional, y si los dependientes aspiraban a algún tipo de ascenso, no podían cuestionar ese españolismo integrista, y mejor aún era si lo compartían (aunque esto no quita que no fuera real el sentimiento subjetivo).

32 Medina Hernández, "Cuba, Canarias y la prensa, en el contexto del 98”, p. 1.

33 Según datos citados en el texto de Medina Hernández, (p. 2), en la segunda mitad del siglo XIX habían emigrado desde Canarias a Cuba entre 50000 y 60000 personas (contabilizando tanto las que se instalaban allí para residir como las que retornaban). Las relaciones económicas entre ambas eran fundamentales para la estabilidad canaria, no solo por los vínculos comerciales mutuos, sino también por el envío de remesas que llegaban desde Cuba a socorrer a los canarios que permanecían en el continente europeo y por el 
por un lado, a que muchos canarios intentaran sostener los nexos tal como existían antes de la guerra. Pero, por otra parte, el territorio canario contaba con cierto estatus o cualidad peculiar dentro del Estado español dado que, si bien era parte constitutiva e integrante en igualdad de condiciones que el resto de la península, su distancia física y cultural, más las marcas de su historia, hacían que su gente pudiera empatizar con el sentimiento de quienes padecían cierta postergación. Esto hizo que muchos de quienes habían migrado a Cuba se identificaran con el ideal emancipatorio de Martí, ya que "quizá desde sus tierras de origen ya se sentían colonizados, y ahora allí sufrían al parejo de cualquier cubano humilde, y mucho más que cualquier cubano rico, las injusticias y los desatinos del gobierno español". ${ }^{34}$

Esta dualidad hará que, paradójicamente, el contingente canario desarrolle un importantísimo rol tanto dentro del ejército oficial español, por ejemplo, en el Batallón de Guerrilleros de Canarias, como a su vez en el ejército contrario a favor de la revolución, alcanzando varios de ellos el grado de Generales. Por lo tanto, si bien en el presente apartado destacamos su participación en el bando separatista, en el siguiente veremos, al contrario, cómo algunos de los medios de prensa canarios más renombrados e influyentes argüirán con fuerte ímpetu contra la independencia antillana.

\section{PERIOdismo REVOLUCIONARIO VS. PERIODISMO REACCIONARIO: el discurso de Patria en contraposición a la PRENSa OFICIAL ESPAÑOLA}

Una de las características que hace tan especial historiográficamente a la guerra de Cuba, es el papel protagónico que ha ejercido la prensa por primera vez en el desarrollo de una contienda bélica. Al respecto, se ha estudiado el proceder de los medios estadounidenses - especialmente los comienzos de la denominada prensa amarillista - durante la última etapa del conflicto, sobre todo con relación a cómo se creaba un clima favorable en la sociedad norteamericana a la intervención de los Estados Unidos en la batalla. Secundariamente se ha contemplado el papel de los medios españoles, pero centrando los estudios también en el último año del conflicto, observando cómo la prensa tematizó sobre el fenómeno que en España se conoció como el Desastre del 98 (en tanto representaba la pérdida de sus últimas colonias y el colapso definitivo del imperio). 
Sin embargo, hay una carencia de estudios sobre la propia prensa cubana - en lo que concierne a todo el período- resultando esto paradójico, ante el innegable protagonismo de los propios cubanos en dicho proceso histórico $y$, por ende, ante la importancia de conocer los discursos que circulaban al interior del grupo combativo. Aquí consideramos elemental analizar las ideas que se difundían y configuraban la perspectiva endógena del movimiento, ya que fue la radicalidad de su ideología la que animó a dicho grupo a devenir en actor revolucionario a partir de una praxis que desafió el statu quo y provocó una ruptura en el devenir de la historia.

Como contrapartida, resulta interesante examinar también las voces opositoras, ya que fue la confrontación entre partes la que ocasionó el conflicto. La influencia de ambas prensas ha sido fundamental para el inicio y desarrollo de la guerra: la separatista animando el comienzo de la revolución armada, y la peninsular oficial exigiendo una contrarrevolución reaccionaria que reprimiera enérgicamente el movimiento. En efecto, desde Patria particularmente, se desplegaron toda una serie de estrategias persuasivas específicas orientadas a los diferentes grupos sociales, y paralelamente se dedicaron hondos esfuerzos a contrarrestar una serie de argumentos presentados por los medios rivales.

En este trabajo analizaremos puntualmente cuáles fueron los argumentos que el principal órgano separatista proporcionó a favor de la independencia de la isla dirigiéndose a un grupo en particular: el de procedencia española. A su vez, contrastaremos su discurso con el de otros periódicos peninsulares, estableciendo un diálogo imaginario, una discusión en la que se enfrentan perspectivas opuestas y se disputan sentidos y representaciones. Aunque nuestra fuente documental primara de análisis es el periódico Patria, esta comparación será posible gracias a que contamos con una rica bibliografía de autoría española que analiza cómo se han posicionado diversos periódicos hispanos en relación con este conflicto.

Al respecto, resultan pertinentes algunas aclaraciones sobre nuestro recorte o selección para el análisis de la prensa peninsular. En primer lugar, debemos repetir que existieron numerosos periódicos en España que escaparon a la lógica que aquí analizaremos y realizaron una lectura de gran profundidad y seriedad sobre el asunto cubano, a veces incluso hasta disidente. No obstante, aquí focalizaremos únicamente en los que se encuadraron en la mirada oficial o hegemónica porque son los que permiten construir ciertas antinomias discursivas, y, sobre todo, porque fue su discurso el que se impuso con mayor eficacia y predominó sobre otros al corresponderse con el accionar gubernamental sobre la realidad. Es decir, atenderemos a los medios conservadores y liberales, en tanto encarnaban el ideario de los grupos dominantes que tenían representación en el gobierno y, por ende, decidían sobre el destino de la nación. 
Por otra parte, en cuanto a los periódicos que se utilizarán para ilustrar el proceder de la prensa hispana en la época, hemos consultado todos los trabajos que hallamos sobre la prensa española en relación con la guerra de Cuba, y esto dio como resultado un corpus periodístico muy favorable en relación a su distribución geográfica. Así, citaremos los diarios de mayor influencia e importancia de las regiones de Castilla y León, Galicia, Asturias, Madrid, Andalucía, Canarias, etcétera. De esta forma, podremos comparar distintos estudios sobre prensa en diversas comunidades españolas construyendo una mirada de conjunto que se sostiene sobre una gran variedad de análisis de casos particulares.

Como ya hemos dicho, aquí analizamos el Patria, de Martí, es decir, los años en los que el periódico estuvo bajo su dirección, entre 1892 (año de fundación) y 1895 (año de su muerte en batalla). Etapa que denominamos como los albores de la guerra y que consideramos clave, porque es allí cuando se produce un salto cualitativo en la gestación del ideario independentista y en la organización de la revolución, gracias a la labor de Martí y su creación del PRC. Sin embargo, en cuanto a la prensa española, como hemos señalado antes, no existen trabajos que analicen la etapa inmediatamente previa al estallido de la contienda; por el contrario, algunos contemplan la temporalidad completa del conflicto bélico (1895-1898), mientras la mayoría se centra sólo en 1898 . En efecto, luego de una ardua revisión bibliográfica hemos distinguido y abstraído únicamente las referencias a 1895.

De esta manera, el desfase temporal resulta mínimo, sobre todo en relación con los tópicos objetos de la comparación. Como veremos, la mayoría de las cuestiones que contrastaremos refieren a nociones conceptuales generales, por ejemplo, sobre las causas y aspiraciones de Cuba al iniciar la revolución, sobre los propios combatientes cubanos y las cualidades de cada uno de los ejércitos, sobre el carácter del Estado Español y su pretendida unidad nacional, entre varias otras. Consideramos que estos temas resultaron relativamente estables durante el período de una misma guerra, y no cuentan con una temporalidad de cambio vertiginosa que imposibilite su comparación, como resultaría de comparar, por ejemplo, las crónicas del acontecer bélico que sí cambian con una gran celeridad y frecuencia prácticamente diaria. Dicho todo, iniciaremos con el análisis.

Al comenzar a examinar el mensaje que Patria puso en circulación, observamos que, para contar con el apoyo de un número considerable de españoles, se encargó de clarificar, en primer lugar, que la guerra que se organizaba no se proponía ir en contra de los españoles como pueblo, sino contra un gobierno colonial que denigraba tanto a españoles y cubanos por igual. Se explicaba que las variadas situaciones de injusticia y opresión que Cuba sufría por parte de la administración de ultramar, las que justificaban el 
desarrollo de la revolución, afectaban de la misma forma a los isleños como a los españoles que allí vivían. Con esto, se buscaba lograr un sentimiento de empatía y unidad, gestar una causa común e inspirar conciencia de que no era unos contra otros que debían luchar, sino juntos en calidad de hermanos, contra un sistema que los sojuzgaba y sólo favorecía a un reducido sector de la sociedad, además del gobierno peninsular:

Nada menos que enemigo de Cuba sería quien pretendiese levantar una valla funesta entre cubanos y españoles (...) cuando oprimidos por igual bajo la tradición española, con su séquito de contratistas, beneficiarios y militares, el hijo de Cuba y el de España, y cerrados a ambos por igual el porvenir legítimo y su entidad humana, líganse el cubano y el español por el bien de la tierra común y la rebelión del decoro, contra el sistema incurable e insolente de gobierno que les ahoga la personalidad, anula el esfuerzo de su industria, cría a los hijos sin rumbo en el hogar inquieto, y les pudre el aire que respiran. ${ }^{35}$

Observamos que este mensaje, perteneciente al primer año de Patria, se dirige sobre todo al pueblo llano, a los sectores populares, a los españoles trabajadores, tanto a aquellos residentes en la isla y que formaban parte de la sociedad cubana, como incluso también a los que vivían en la península. Las referencias al séquito de contratistas, beneficiarios, y militares, buscan dar cuenta que, lejos de ser el pueblo español en su conjunto el que disfrutaba de los frutos de la explotación española sobre Cuba, los beneficiarios eran grupos de individuos demarcados y específicos. Al interior de la isla eran sobre todo los elementos políticos, militares, y comerciantes favorecidos por el monopolio español, mientras que en España las ventajas se distribuían muy inequitativamente, concentrándose en las burguesías de ciertas regiones particulares.

Resulta oportuno añadir que, como afirma Espadas Burgos, ${ }^{36}$ la política de la Restauración en España se asentaba sobre la comunión de intereses siderúrgicos del País Vasco, los textiles de Cataluña, y los cerealistas de Castilla y León. Así, los mercados ultramarinos, pero especialmente el cubano, al ser un mercado coactivo casi en términos monopólicos, constituía un elemento de estabilidad para el régimen, al otorgar ganancias aseguradas a los sectores vinculados a los intereses aludidos, especialmente productores y comerciantes.

En las regiones especialmente sensibles a los cambios económicos que la pérdida del vínculo colonial podía causar, la prensa sería sustancialmente virulenta a la hora de defender la perpetuación del orden existente en Cuba, justificándolo en nombre del bien común. De manera estrategica, los discursos

"La Mechianza"; Patria, núm. 34, Nueva York, 1 de noviembre de 1892.

Citado en Blanco Rodríguez y Alonso Valdés. Presencia castellana en el "ejército libertador cubano" (1895-1898), p.77. 
que circulaban por los canales oficiales afirmaban que tal cuestión era transcendental para toda la sociedad en su conjunto y constituía una necesidad vital independientemente de los estratos sociales, afectando a la totalidad de la estructura socioeconómica.

Distintos autores españoles destacaron esta idea en torno a la generación de una falsa conciencia que los medios periodísticos estimularon, y que encubría unos riesgos y pérdidas materiales para ciertos grupos particulares, aunque se plantearan como generales. En la obra de perspectiva marxista La prensa burguesa en Canarias ante la guerra de Cuba, sus autores, refiriéndose a la realidad hispana en su conjunto, afirman que: "la burguesía agredida utiliza todos sus mecanismos ideológico-políticos para implicar por el camino del sentimentalismo - y en caso necesario de la coacción — al pueblo en defensa de sus intereses...". ${ }^{37}$

En el caso de la Comunidad de Castilla, por ejemplo, Santiago de Alba (secretario de la Cámara de Comercio de Valladolid y a la vez gerente del periódico El Norte de Castilla) advertía que la disminución del comercio triguero perjudicaría por igual a terratenientes como a jornaleros, a los dueños de las fábricas como a los obreros, y que se requería la guerra colonial en ultramar para evitar al interior una guerra social. ${ }^{38}$ De esta idea se desprende, en primer lugar, que era conveniente que el padecimiento lo sufrieran los de afuera antes que los de adentro, y además que, si, por el contrario, la crisis rebasaba en el interior, todo el entramado social erupcionaría poniendo en riesgo la estructura socioeconómica en su conjunto (y los privilegios de clase principalmente).

Retomando a Patria, de la última cita se extrae la idea de que no habría motivo, entonces, para diferenciar en función del criterio de nacionalidad en dicha coyuntura histórica, siendo otros los factores determinantes para posicionarse a favor o en contra de la revolución. Los sectores beneficiados por el poder explotaban y abusaban, sin distinción de origen, las fuerzas de trabajo y recursos de la isla a su favor, aunque lo ocultaran en sus medios de prensa, justificando sus posiciones en nombre del bien nacional. En el mismo sentido se inscribe el siguiente párrafo:

El mundo tiene dos campos: todos los que aborrecen la libertad, porque solo la quieren para sí, están en uno; los que aman la libertad y la quieren para todos, están en otro. En Cuba, como en Puerto Rico, los dos campos son esos: españoles

37 Fernández Expósito; Cabrera Acosta; González. La prensa burguesa en Canarias ante la guerra de Cuba, p. 12.

38 Blanco Rodríguez y Alonso Valdés. Presencia castellana en el "ejército libertador cubano" (1895-1898), p. 75. 
y criollos del alma autocrática (...) y los cubanos y los naturales de España que bajo ella ven ofendidas sus almas libres... ${ }^{39}$

Es decir, el criterio que distinguía a unos hombres de otros no tenía que ver con su lugar de nacimiento, sino con una resolución de carácter ético, que hacía que unos se hallasen oprimidos y desearan construir un mundo más justo y democrático, mientras otros abusaran de esa inequidad en su provecho. Esta idea sostenía que los españoles y cubanos, cuyas intenciones fueran nobles y generosas, podían perfectamente convivir y construir juntos un orden de cosas diferente. Se remarcará con especial énfasis que la república futura que se pretendía fundar estaría abierta a todos los hombres que quisieran vivir en ella y no prevalecería ninguna razón de diferenciación sobre criterios nacionales, raciales, sociales, ni de ninguna otra índole que no fueran la bondad, la laboriosidad y la honestidad. Los españoles de buena madera, al decir de Patria, "son hermanos nuestros, y en Cuba Independiente han de encontrar libertades y garantías para su persona y sus intereses". ${ }^{40}$

Con estas afirmaciones se buscaba contrarrestar los temores a un odio injustificado, o a una política agresiva, por parte de los cubanos hacia los españoles en el trascurso de la guerra o al término de ésta, ya que la mayoría de los medios opositores vociferarían en este sentido. La campaña mediática que se gestó en España, desde los comienzos del conflicto, atribuyó características brutales al ejército revolucionario, buscando demonizar al supuesto enemigo, con el fin de incentivar su desaprobación por parte de la sociedad.

Existen diversos estudios que analizan cómo distintos periódicos españoles han representado al conflicto cubano, y la mayoría coinciden en señalar que las noticias sobre Cuba estarán marcadas por un discurso no sólo patriótico, sino también patriotero, al que podemos definir por la exaltación de las cualidades supuestamente superiores de la propia identidad nacional, y a su vez por la denigración violenta del otro. Tal es el caso de Teresa Piñeiro-Otero, quien afirma: "las principales cabeceras de Madrid, así como la mayor parte de las publicaciones periódicas de toda España, mantuvieron una postura de patrioterismo barato". ${ }^{41}$

Podemos citar varios trabajos específicos sobre las diferentes comunidades de España para ejemplificar estas afirmaciones generales sobre la prensa hispana. La autora antes nombrada ${ }^{42}$ en su análisis sobre los principales diarios de Galicia — el Faro de Vigo y La Voz de Galicia — afirma que siempre

\footnotetext{
39 “Un español"; Patria, núm. 6, Nueva York, 16 de abril de 1892.

"De la buena madera", Patria, núm. 67, Nueva York, 24 de junio de 1893.

Piñeiro-Otero, "Héroes, filibusteros y villanos. Representaciones y mitos de la Guerra de Cuba en la prensa gallega del momento (1895-1898)", p. 113. 
las alusiones a los independentistas utilizan términos como malhechores, asociando directamente el separatismo con el bandolerismo. En todos los rotativos observados, los insurrectos son representados como diabólicos, miserables, crueles, ladrones, asesinos, forajidos, impíos, bárbaros, entre otros apodos de similar calibre.

Lo mismo sucede con la prensa hegemónica de Castilla y León, ya que Blanco Rodríguez y Alonso Valdés afirman que en El Norte de Castilla el concepto que se difunde sobre los independentistas es "partidista, vejatorio y racista", se les define como una "horda sin disciplina compuesta de aventureros de toda raza, de extranjeros, bandidos y fanáticos...", ${ }^{43}$ capaces de los peores actos y dignos de temor. La adjetivación de éstos será habitualmente a través de epítetos denigratorios: filibusteros, criminales, salvajes, sanguinarios, entre otros.

Especialmente graves y ofensivas son las referencias a los grupos afrocubanos, identificados con la barbarie, como si portaran una bestialidad innata en la sangre. La población negra constituyó efectivamente la mayor parte del esfuerzo del ejército revolucionario, por lo que se dirigieron los peores insultos contra ésta, los cuales expresaron el trasfondo racista y discriminatorio presente en la mentalidad de la época. Los autores atestiguan que el Norte de Castilla atribuye a la gente de color los instintos más bajos y las cuotas más altas de ferocidad y salvajismo, y que pretende, al igual que otros medios, presentar la guerra como un enfrentamiento entre blancos españolistas $y$ negros y mulatos cuyo odio y resentimiento hacia el blanco sería utilizado por algunos criollos con intereses bastardos. ${ }^{44}$

Lo mismo ocurrió con la prensa de Asturias, en donde la cuestión cubana predominó sobre otros asuntos y repitió los patrones discriminatorios que mencionamos. El autor Erice Sebares ${ }^{45}$ afirma que el tono triunfalista presentó el conflicto como un enfrentamiento entre heroicos españoles y cobardes e ingratos mambises, resaltando la agresividad de estos últimos. Esta adjetivación se agrava por el componente racial, instalando la idea de que había que salvar a Cuba de que cayera bajo el dominio de los negros. Ya en 1895 las alusiones tanto al supuesto salvajismo de los cubanos rebeldes y de sus cabecillas de color era un rasgo constante: en el periódico de Oviedo El Carbayón podía leerse: "Ya no se conforman con los robos, incendios, saqueos, asesinatos aislados y la destrucción (...) sino que apelan a un procedimiento salvaje que ni los moros

\footnotetext{
43 "Opiniones interesantes", El Norte de Castilla, Valladolid, 8 de julio de 1896, citado en Blanco Rodríguez y Alonso Valdés. Presencia castellana en el "ejército libertador cubano" (1895-1898), p. 101.

44 Blanco Rodríguez y Alonso Valdés. Presencia castellana en el "ejército libertador cubano" (1895-1898), p. 102.

45 Erice Sebares, "Los asturianos ante la guerra de Cuba (1895-1898)", pp. 147-164.
} 
emplearon cuando la guerra de Melilla: a la dinamita...". ${ }^{46}$ Eran constantes las referencias a las hordas africanas que protagonizaban la insurrección, y especialmente apasionadas fueron las celebraciones por la muerte de Maceo, dada su condición racial.

En Madrid, donde se hallaban los medios más influyentes a nivel nacional por su carácter capitalino, el periódico conservador La Correspondencia de España, publica en 1895 una entrevista donde Montoro afirma que la rebelión está destinada a fracasar por la incompetencia de sus protagonistas: "aseguro que es un error la rebelión existente en el Departamento Oriental, y no puede triunfar: es principalmente una revuelta de negros..." ${ }^{47}$ Acto seguido, reafirma la idea: “¿Quiénes son los jefes de la revuelta? Los dos Maceos, negros por su sangre y sus simpatías (...) Rabí, Goulet, Miró, y tantos otros, son todos negros". ${ }^{48}$

En el mismo sentido, Teresa Piñeiro-Otero destaca que también la población china, junto con la negra, fue víctima de una de las adjetivaciones más segregacionistas y denigrantes, y que "la prensa gallega adoptó la costumbre de referirse a los líderes insurgentes por su grupo racial de pertenencia, siempre que éste no fuese el imperante". ${ }^{49}$ Ambos grupos poblacionales representaban dos de los colectivos más relegados socialmente y explotados como fuerza de trabajo, hallando en la lucha independentista una esperanza de dignificación y adquisición de los derechos que les eran negados. Las narraciones sobre las acciones bélicas destacan su crueldad y sed de venganza ante el supuesto rencor que los animaba.

Dejando de lado la visión oficial peninsular y retomando la perspectiva separatista, Patria advierte todos los prejuicios y falsos estereotipos arraigados en la sociedad, que iniciado el conflicto explotarían los sectores más conservadores para atemorizar a la sociedad. Así, anticipa los argumentos y falacias que se usarían en contra de la causa y antes de iniciada la guerra publica lo siguiente:

Los cubanos no hacemos, ni queremos, campaña de exterminio de nuestros padres, ni nos animan sentimientos de odio y de desprecio a nuestros antepasados; a España, es decir, a su explotación en América, es a la que combatimos: para el bienestar de peninsulares y de criollos es que convidamos a nuestro país al sacrificio (...) Degollar, quemar, aniquilar, no es nuestro programa, sino conservar,

46 "Carta de Cuba", El Carbayón, Oviedo, 12 de noviembre de 1895, citado en: Erice Sebares, "Los asturianos ante la guerra de Cuba (1895-1898)", p. 156.

47 "Cuba", La Correspondencia de España, Madrid, 12 de junio de 1895.

$48 \quad$ Ibid.

49 Piñeiro-Otero, "Héroes, filibusteros y villanos. Representaciones y mitos de la Guerra de Cuba en la prensa gallega del momento (1895-1898)", p. 124. 
fundar, aunar, levantar, engrandecer. Con los españoles buenos queremos hacer la patria; pero con o sin los españoles estamos dispuestos a constituirla. ${ }^{50}$

Son múltiples las notas que Martí publica para derribar los preconceptos existentes y combatir la falsa información que circularía de manera intencional para desprestigiar la causa. En un editorial de Patria se cita una nota del periódico francés Le Monde Ilustré que refería al miedo por parte de los españoles a ser maltratados después de una posible revolución cubana; al respecto Patria contesta:

Pero nuestros padres (...) los que aman en sus hijos, con esa cabezada romántica de español castizo, la potencia de rebelión que desde su aldea infeliz y la quinta despótica y el arranque sangriento a las Américas ardió en su propia alma, los españoles llanos, los españoles buenos, los españoles trabajadores, los españoles rebeldes, esos no tendrán nada que temer de sus hijos, no tendrán nada que temer de un pueblo que no se lanza a la guerra para la satisfacción de un odio que no siente, sino para el desestanco de su persona y para la conquista de la justicia. ${ }^{51}$

El lema libertad sin ira pretendía guiar una lucha lo más breve y menos nociva posible y una de las recomendaciones de Martí publicadas en Patria decía: "Que continuamos la revolución sin odio a los españoles, y sin lisonja, con el propósito sincero de atraer a la neutralidad, o a la independencia (...) a los españoles, arraigados en Cuba, o deseosos de vivir en ella sin perturbarla ni dañarla" ${ }^{52}$ Se insistía también en reducir al mínimo los efectos perjudiciales del conflicto bélico sobre la población, en la que lógicamente se incluía a los hispanos, y de asegurarles a estos últimos que serían bienvenidos en el proyecto que se perseguía. Éste se fundaba en el deseo de democracia, justicia y equidad, aspiraba a gestar una nación sin enemigos ni resentimientos, donde se respetaran los derechos de todos los diversos elementos y pudieran convivir en paz y armonía.

Sin embargo, estos móviles profundos e ideológicos tras la revolución - que se enraizaban en toda una historia de luchas y resistencias — no serían así percibidos ni comprendidos por los medios opositores liberal-conservadores, que no harían siquiera el intento de analizar, para entender, la perspectiva del pueblo cubano. Al contrario, usarían todos sus recursos para desprestigiar la causa y sus adherentes, negándoles dignidad y restándole importancia. Blanco Rodríguez y Alonzo Valdés afirman que en la mayoría de los casos el tema de la independencia cubana en la prensa española no fue tratado con la profundidad ni seriedad que ameritaba. Además, continuamente se brindaba

\footnotetext{
50 “A los españoles”, Patria, núm. 116, Nueva York, 16 de junio de 1894.

51 "La revolución”, Patria, núm. 103, Nueva York, 16 de marzo de 1894.

52 “Recomendaciones", Patria, núm. 26, Nueva York, 3 de septiembre de 1892.
} 
información falsa o infundada, y se ocultaba la que pusiera en tela de juicio la supuestamente inquebrantable soberanía de España.

En su libro sobre la prensa de Sevilla, ${ }^{53}$ Sevilla Soler analiza el tratamiento de la cuestión cubana en los principales medios de la capital andaluza, con base en los diarios El Noticiero Sevillano, El porvenir, El progreso y El Baluarte. La autora coincide en que desde el principio del conflicto se instaló la idea de que la rebelión sería sofocada velozmente dada la superioridad militar de las fuerzas hispanas. Se generó una confianza excesiva que consideraba al triunfo español totalmente inevitable (con la única excepción de algunos republicanos y la prensa obrera). En consonancia, los medios más prominentes de Galicia, al comienzo, se negaron a catalogar la insurrección cubana como un verdadero movimiento nacional de carácter popular. Al contrario, los primeros enfrentamientos bélicos se enunciaron en los siguientes términos: “...ocurrió un pequeño encuentro entre una partida de malhechores y algunas fuerzas del Ejército (...) apareció otra partida separatista al mando de Manuel García, la cual se dedica al pillaje y al robo". ${ }^{4}$

Observamos una completa deslegitimación de las fuerzas mambíes, que en ningún momento se les posiciona al nivel de un ejército, sino que se les infravalora en lo que respecta a su potencial militar, su representatividad social y sus propósitos ideológicos, negándoles cualquier posibilidad de desafiar a las tropas oficiales y, por ende, a la entereza de la patria. Los principales medios de las distintas comunidades de España vociferaron en este sentido durante toda la primera etapa del conflicto, afirmando con total seguridad que la situación se encontraba bajo control español.

El Norte de Castilla, por ejemplo, al inicio de la guerra negó cualquier importancia al levantamiento, pues lo consideraba mera obra de bandidos que de ninguna manera peligraría la integridad del territorio nacional, ya que, al decir del diario, Cuba era en su espíritu cada día más española. Sólo hacía falta una veloz represión sobre las acciones de algunos rufianes y desaprensivos. Su cobertura de la realidad estuvo mediada por un velo patriótico falto de sentido crítico; en su lugar abundaron, además de difamaciones a los combatientes cubanos, referencias a las glorias pasadas de la nación y a las supuestas y altisonantes virtudes del soldado peninsular.

Así, observamos los dos componentes principales de la lógica que reprodujeron la mayoría de los medios españolistas ante el conflicto: la desacreditación del otro y la exaltación de lo propio. Este último elemento lo

53 Sevilla Soler, La Guerra de Cuba y la Memoria Colectiva. La crisis del 98 en la prensa sevillana, pp. 30-31.

54 El Faro de Vigo, 28 de febrero de 1895, citado en Piñeiro-Otero, "Héroes, filibusteros y villanos. Representaciones y mitos de la Guerra de Cuba en la prensa gallega del momento (1895-1898)", p. 121. 
vemos continuamente y en todas formas: se alaban las cualidades del ejérctito y del pueblo español, se poetiza sobre el sentir nacionalista, se encumbran las virtudes de la cultura hispana, y se resalta la entrega desinteresada de la comunidad ibérica a la lucha por el honor de su patria. La arenga al orgullo nacional se empeñó en fomentar un frenesí en torno a la guerra, buscando que el pueblo se movilizara cuasi encandilado hacia la misma.

El diario madrileño La correspondencia de España, apenas iniciada la guerra, se refiere a los soldados españoles con la siguiente descripción: "llenos de vida y de entusiasmo patrio, esos batallones de cazadores ágiles, impetuosos, que desafían alegremente la muerte por las armas o por el clima, son de la madera de los que tantas proezas han realizado y tanta gloria han conseguido en la península". ${ }^{55}$ Vemos cómo se enaltece a los combatientes y se instaura una actitud ideal que sirve de ejemplo a imitar. También hallamos de forma recurrente relatos de situaciones supuestamente destacables por el nacionalismo que evidencian: tal es el caso de una mujer que al ir a despedir a los batallones que se dirigían a Cuba, les dice: "No acordarse de vuestras novias, y todo cuanto encontréis en Cuba, por delante que sea contrario a España, destruidlo sin compasión". ${ }^{56}$

En las Islas Canarias, por incluir otro ejemplo, según los estudiosos del tema, ${ }^{57}$ se volcaron todos los recursos discursivos y alegóricos para alentar al ejército a que contribuya con su abnegación y obediencia: "La prensa canaria de estos años es una continua remembranza de la grandeza española, del pasado glorioso, de los peligros sorteados juntos, de la unidad católica y sagrada...". ${ }^{58}$ Según los autores, el fanatismo reemplazó a la objetividad, y aunque ésta no exista en estado puro en la realidad, aquí no hubo siquiera una intención de aproximarse a ella dentro de límites plausibles; en su lugar, primó una excesiva tergiversación intencionada.

En el mismo sentido, la mayoría de los medios hispanos exagerarán desde el comienzo la supuesta avalancha de voluntarios enlistados para ir a Cuba, que no era ni tan cuantiosa ni tan espontánea como afirmaba la prensa.

$55 \quad$ La Correspondencia de España, 18 de abril de 1895.

$56 \quad$ Ibid., 15 de agosto de 1895.

57 Los periódicos sobre los que los autores Fernández Expósito, Cabrera Acosta, Gonazález basan las conclusiones de su libro La prensa burguesa en Canarias ante la guerra de Cuba son los siguientes: Diario de Avisos (independiente) de Santa Cruz de la Palma, Heraldo de Canarias (liberal) de Santa Cruz de Tenerife, Cronista de Tenerife (liberal) de Santa Cruz de Tenerife, El Adalid (liberal-conservador) de Santa Cruz de la Palma, La Opinión (liberalconservador) de Santa Cruz de Tenerife, La Patria (liberal) de Las Palmas, Diario de Tenerife (liberal-conservador) de Santa Cruz de Tenerife, el Liberal de Tenerife (liberal) de Santa Cruz de Tenerife y El Cronista (conservador) de Las Palmas.

58 Fernández Expósito, Cabrera Acosta y González, La prensa burguesa en Canarias ante la guerra de Cuba, p. 12. 
Además, una vez iniciado el conflicto, para mantener el fervor en alto se manipularía impúdicamente la información, negando las cifras de muertes por enfermedades presentadas por algunos periódicos, considerando fiables sólo las gubernamentales. Además, los medios oficialistas no sólo ocultarían las denuncias respecto a las condiciones deplorables a las que se sometían los combatientes, sino incluso, se jactarían del buen estado anímico y de salud del ejército, lo que era totalmente falso: “...se les ve animados, ágiles, robustos, alegres. Rebelan satisfacción en el semblante y gozan de salud, dando el menor contingente posible a los hospitales". ${ }^{59}$

Este optimismo inducido por la prensa hispana perduraría a lo largo de casi toda la guerra — más allá de algunos momentos fluctuantes— ${ }^{60}$ convirtiéndose en suicida al comenzar la intervención de Estados Unidos, episodio a partir del cual la adulación patriótica se acrecienta aún más. Las ilusiones se desvanecerían de un soplo con las primeras derrotas frente al nuevo oponente (que darían lugar a lo que se conoció como el Desastre del 98 y revelarían lo intencionalmente artificiosas e ingenuas que habían sido las esperanzas de victoria). Aun así, a pesar del fracaso inminente, muchos medios sostuvieron igual la determinación por la guerra por una supuesta cuestión de dignidad, afirmando que era preferible perder, a no ir a luchar con “....un pueblo de dudosa procedencia, y por lo tanto, sin historia....". ${ }^{61}$ Pero la actuación de los medios en torno al año 1898 excede al objeto de este trabajo y cuenta con un campo de estudios mucho más frondoso al respecto. Aquí analizamos los argumentos y discursos que circularon inmediatamente antes y durante la guerra.

Como contrapartida a todo este bagaje mediático, Patria buscará desarticular las construcciones discursivas en torno al mandato ético que exigía la defensa del honor y la grandeza nacional. La nota que publica en 1894 titulada $A$ los españoles — que cita a su vez el artículo Explicaciones

59 Blanco Rodríguez y Alonso Valdés, Presencia castellana en el "ejército libertador cubano" (1895-1898), p. 97.

60 Podríamos decir que 1897 fue el año en que el entusiasmo llegó a sus cotas más bajas, respondiendo a causas militares, económicas y políticas: el "empate técnico" en las armas luego de tres años de lucha, a pesar de las duras medidas de Weyler, que aun así no lograban un avance significativo; la crisis económica provocada por los efectos de la guerra que cada vez se sentían con más fuerza; la muerte de Cánovas en agosto y la posterior aprobación del proyecto de autonomía para Cuba, entre otros. A todo esto, se sumaba la aparición cada vez más frecuente de noticias y testimonios sobre el estado crítico de las fuerzas, la miseria de la guerra y las bajas por enfermedades, pese a los intentos del gobierno por ocultarlos. No obstante, con la intervención de los Estados Unidos al año siguiente, el frenesí popular resurgiría de manera generalizada con más ímpetu que antes, a excepción sólo de algunos sectores muy puntuales. Erice Sebares, "Los asturianos ante la guerra de Cuba (1895-1898)", pp. 147-164.

61 El Progreso, 21 de abril de 1898. Citado en Sevilla Soler, La Guerra de Cuba y la Memoria Colectiva. La crisis del 98 en la prensa sevillana, p. 73. 
y advertencias del periódico Cuba - busca arrojar cierta claridad sobre las intenciones que persigue el Ejército Revolucionario y rebatir contra los argumentos de la oposición:

La codicia tenaz, el fanatismo, que tiene por ídolo el mito de la integridad nacional, os ciegan y enloquecen ¡oh españoles! ¡Volved en vosotros! Nuestra causa es también vuestra causa: es la causa de la humanidad. (...) No os sonrojáis al considerar que a fines del siglo XIX os empeñáis en seguir siendo para América lo que en los primeros tiempos fueron para España los fenicios, los rodios, los samios, los focenses, lo que con mejor éxito fueron los cartagineses, lo que finalmente fueron los romanos? (...) ¡Sed justos: la integridad nacional que defendéis es una farsa con que unos cuantos miserables os fanatizan para que seis los instrumentos de sus infames especulaciones! ${ }^{62}$

Vemos cómo se problematiza en torno al tan arraigado y recurrente argumento de la integridad nacional, y se cuestiona ese ideal comparando la pretensión española sobre Cuba con la dominación que España misma sufrió en el pasado por otros pueblos ajenos. También será usual que Patria, para interpelar a diferentes grupos de españoles y puedan entender o empatizar con la posición independentista, haga referencia al sentimiento de opresión que muchas comunidades al interior de la propia península sentían respecto al centralismo que imponía el Estado español. Para finales del siglo xIX existía en diferentes regiones hispanas un deseo separatista y una autopercepción identitaria diferencial, e incluso marginal, que daba forma a distintos nacionalismos disgregadores. Patria recurrirá en varias ocasiones a tal situación como recurso comparativo:

en la misma España hay el deseo justo en comarcas enteras, laboriosas, y emprendedoras, de separarse de una unidad ficticia que solo sirve para conservarla como parte integrante de una potencia de segundo orden, en el último puesto del viejo mundo: ayer eran los catalanes que aspiraban a su principado aparte y hasta a la anexión a Francia. Galicia y Aragón, descontentas con el régimen centralizador piden sus fueros conculcados; hoy se menosprecia a España en la misma España, clara y terminantemente se reclama la independencia total y absoluta de Vizcaya (...) iQué podríamos decir nosotros los cubanos! $!^{63}$

Efectivamente, y a pesar de la preponderancia de ciertos discursos en torno a la unidad nacional, un gran número de españoles se sintió interpelado y aprehendió las ideas transmitidas por el grupo revolucionario, destacándose

\footnotetext{
62 “A los españoles”, Patria, núm. 116, Nueva York, 16 de junio de 1894 (cita del artículo Explicaciones y Advertencias, del periódico Cuba).

63 "Desastres y engaños", Patria, núm. 116, Nueva York, 16 de junio de 1894.
} 
aquellos provenientes de las zonas más rezagadas de España (muchas portadoras también de un anhelo de independencia, o por lo menos de mayor autonomía). Algunos avalaron la lucha involucrándose en ella activamente, participando en la toma de armas, y otros lo hicieron discursivamente o a través de distintas manifestaciones de apoyo. Estas situaciones se dieron con mayor frecuencia tanto dentro de Cuba como en las comunidades de inmigrantes hispanos y cubanos en los Estados Unidos, sobre todo en Tampa y Cayo Hueso, donde tenían lugar las actividades de los clubes políticos que integraban el PRC. Patria da cuenta de esta aprobación por parte de peninsulares, que era expresada públicamente en las reuniones del partido:

La demostración política llevada a cabo por el elemento genuinamente español honrado y liberal de Tampa en pro de la política revolucionaria proclamada por el Sr. Martí, ha señalado el comienzo de una era vivamente anhelada (...). Así lo comprendieron con sagaz penetración los obreros españoles de Tampa y no tuvieron por qué callar en el momento más propicio para manifestarse. Al massmeeting dado allí la noche del 28 último acudieron en manifestación solemne e imponente. La justicia de nuestra causa fue por ellos reconocida y proclamada. ${ }^{64}$

El hecho de difundir estas expresiones de apoyo por parte del periódico seguramente pretendió exponer la justicia de la causa, mostrando que hasta era reconocida por los propios españoles, y actuar como una especie de estímulo para que otros también se atrevieran a manifestar su empatía. Sin embargo, en el número siguiente de Patria se denuncia la represalia que ha tomado el elemento conservador hispano en Estados Unidos ante la demostración de apoyo al independentismo por parte del grupo de españoles de Tampa. Sus declaraciones a favor de Martí provocaron medidas coercitivas sobre los obreros en la fábrica de tabaco donde trabajaban, que a su vez provocaron la declaración de una huelga como protesta por parte de españoles y cubanos conjuntamente.

Este tipo de situaciones punitivas, que como vemos ya tenían lugar antes de iniciada la contienda, una vez desatada la coyuntura bélica se convertirán en una constante. Existía la convicción en amplios sectores españoles de que debían ejercerse severos castigos como medio de disciplina para quienes se desviaban del camino correcto. Incorporamos antes una cita publicada en el Norte de Castilla planteando que, si el delito del separatismo era considerado grave de por sí, doblemente delictivo era si se practicaba por españoles, a causa de la traición moral que encubría.

El gobierno español también exigiría un férreo control sobre la prensa para que no divulgara mensajes que pudieran deshonrar la causa ibérica,

64 “Excursión Política”, Patria, núm. 23, Nueva York, 13 de agosto de 1892. 
especialmente cuando, avanzada la contienda, los pronósticos comenzaran a cambiar y las perspectivas no fueran tan optimistas. A medida que surgieron manifestaciones pesimistas o críticas al desarrollo de los hechos, distintas figuras reclamarían una incorruptible lealtad al gobierno por parte de la clase política, y, sobre todo, por parte de los medios periodísticos, rechazando fuertemente las discusiones partidistas o mensajes mediáticos que pudieran socavar la unidad.

Estas exigencias testimonian una clara consciencia y convicción sobre la importancia del papel de la prensa en tanto agente y mediador social, con un poder de impacto fáctico en el pensar y accionar de la sociedad. El Norte de Castilla dictará: "prensa y barcos están igualmente obligados a luchar por la integridad del territorio, unos con los cañones allá contra los barcos filibusteros, otros con la pluma aquí contra la apatía y el egoísmo...". ${ }^{65}$ Ambos bandos advertían sobre la importancia de la propaganda mediática y su influencia en la opinión pública de la época. De la misma manera, Patria establecía: "las grandes ideas no alcanzan acceso en las muchedumbres, hasta que una propaganda constante y abnegada no logra despertar el sentimiento del deber en las conciencias aletargadas por la acción represiva dominante. Nosotros sabemos que la opinión pública es irresistible". ${ }^{66}$

En efecto, el sector militar español protagonizará un proceso de avance y conquista de prerrogativas sobre la prensa mientras sucedía la guerra con Cuba, que Pérez Ledesma ${ }^{67}$ describe como de remilitarización de la política española en una ofensiva sobre el poder civil. Según el autor, habría sido a raíz de un conflicto en el norte de África en 1893, difundido en los medios como la vergüenza de Melilla ${ }^{68}$ que el sector militar introdujo con fuerza en la opinión pública peninsular un discurso caracterizado por una gran virulencia patriótica, una vocación colonialista y un exacerbado nacionalismo belicista. Este episodio habría constituido un antecedente del lenguaje altisonante y catastrófico que tendría su máxima expresión hacia el final de la guerra

65 "Cuestión terminada", El Norte de Castilla, Valladolid, 1 de octubre de 1895. Citado en Blanco Rodríguez y Alonso Valdés, Presencia castellana en el "ejército libertador cubano" (1895-1898), p. 78.

66 "Reflexionemos", Patria, núm. 62, Nueva York, 19 de mayo de 1893.

67 Pérez Ledesma, "La sociedad española, la guerra y la derrota", pp. 91-150.

68 El conflicto estuvo originado por la construcción de fortificaciones militares españolas alrededor de Melilla que desencadenaron la reacción de las tribus del lugar, quienes vieron afectadas sus propiedades y espacios sagrados, y decidieron atacar las guarniciones militares, en el que murieron 18 soldados hispanos y más de 30 resultaron heridos. El gobierno español evitó el uso de la fuerza, y en cambio realizó una reclamación diplomática al sultán de Marruecos, que derivó en un acuerdo entre partes, pero esta actitud fue severamente criticada por la opinión pública española y concebida como una denotación de debilidad que desprestigiaba al imperio colonial. 
hispano-cubana-norteamericana, en torno a la imagen conceptual del desastre del 98, que sería el paroxismo de un malestar con el gobierno, acumulado durante todo el período en el que se prolongó el conflicto. ${ }^{69}$

Las fuerzas armadas españolas no se conformarían con imponer su discurso y su postura de los hechos ante los fracasos militares que se sucedía en Cuba. ${ }^{70} \mathrm{Al}$ contrario, se consideraban merecedoras de un papel mucho mayor en la conducción de la nación, por lo que se produjo una especie de campaña mediática que tomó forma de confrontación entre el poder político y el militar. La prensa había sido un ámbito de disputa tradicional entre militares y políticos, sobre todo a partir de los años 80 cuando se convirtió en una de las áreas más "abiertas" del régimen. En la prensa se expresaban las demandas y perspectivas políticas que el caciquismo y el fraude electoral no dejaban canalizar por otras vías, se podían hallar duras críticas a la monarquía, al ejército y hasta cuestionamientos a la unidad nacional.

En consecuencia, los militares trataron de restringir las opiniones que los perjudicaban usando su recurso por excelencia, la fuerza, en su propia defensa. Ya desde principios de 1895, comenzaron a asaltar la redacción de periódicos que habían osado criticar algún aspecto del ejército, como

69 Algunos de los hechos que agravaron y reflejaron este malestar entre gobierno y ejército fueron, en 1897, las renuncias de dos de los militares y capitanes generales más prestigiosos de España: García Polavieja como gobernador y Capitán General de Filipinas, en protesta por no recibir los refuerzos que necesitaba; Weyler como Gobernador y Capitán General de Cuba, para demostrar su desacuerdo con el gobierno liberal al aprobar la concesión de la autonomía a la isla. Ambos fueron tan aclamados a su vuelta y recibidos con tal popularidad, que se acrecentaron los rumores que presagiaban un golpe de estado. Los enemigos del régimen monárquico creyeron encontrar en el desencuentro entre políticos y militares la chance de conquistar posiciones si canalizaban a su favor la fuerza militar, por lo que alimentaron con sus medios la adulación al ejército. Periódicos republicanos como El Progreso y El País se involucraron en esta apuesta mediática convocando enérgicamente a los oponentes al gobierno a los actos de recibimiento de Weyler, como denunciando la posterior represión estatal de los mismos. Pérez Ledesma, "La sociedad española, la guerra y la derrota", pp. 91-150.

70 Según la perspectiva militar, los fracasos bélicos eran culpa del gobierno parlamentario, al no haber priorizado por años la modernización del ejército, aunque se intentase responsabilizar injustamente a este desmereciendo su entrega y sacrificio. España no habría sido vencida por el enemigo, sino traicionada por los políticos; y las colonias no se habrían perdido por la guerra, sino por la cobardía e inoperancia del gobierno, que ni siquiera les permitió luchar la última batalla, al decidir claudicar ante la derrota de la marina en los primeros dos enfrentamientos con Estados Unidos. De esta interpretación brotó un discurso ultranacionalista y antiparlamentario, que descalificaba la clase política y planteaba la necesidad de una regeneración, que alimentó las sospechas sobre una posible dictadura (aunque al final no se materializó y los militares sobre los que más se especulaba fueron integrados en los partidos constitucionales existentes: Weyler en las filas del Partido Liberal, siendo ministro en el gobierno de Sagasta de 1901-1902 y Polavieja en el Partido Conservador de Francisco Silvela en 1899) Pérez Ledesma, "La sociedad española, la guerra y la derrota”, pp. 91-150. 
la actitud de suboficiales que rehusaban acudir a las Antillas. A su vez, los medios que denunciaron públicamente esta situación de violencia fueron las siguientes víctimas de los ataques; sus edificios fueron destruidos y sus redactores agredidos. Si bien buena parte de la opinión pública liberal reclamó al gobierno de Sagasta que sancionara a los culpables y otorgara garantías de seguridad pública a los periodistas, éste se mantuvo inactivo, atemorizado por los rumores que empezaban a circular sobre un golpe de Estado. ${ }^{71}$

A pesar de estos episodios, la libertad de prensa siguió vigente formalmente a lo largo de la contienda, y con la perpetuación del conflicto por años, varios periódicos expusieron sus críticas a la guerra y sus procedimientos, al sistema de reclutamiento, y al accionar del gobierno, entre otros temas. En estos nuevos casos, sería el gobierno quien también tomaría la represalia y denunciaría a los medios que cuestionaban las instituciones de la nación, encarcelando algunos periodistas, mientras que los grupos militares continuarían practicando la represión de forma directa, manteniendo la costumbre de atacar los locales de los diarios más críticos.

A medida que la derrota con los Estados Unidos se haría inminente, y para evitar sus repercusiones políticas, el gobierno de Sagasta accedería a dar forma legal a la tutela que venían ejerciendo los militares sobre la libertad de imprenta, implantando la censura previa de todas las publicaciones. Con el pretexto de que la capitulación podía ser usufructuada para agitar a las masas por parte de la prensa republicana o carlista, poniendo en peligro el orden social y la monarquía, a mediados de 1898 se impondría el control de toda la prensa periódica, quedando la censura bajo la órbita del ejército, en lugar de la administración civil del estado.

Todos estos avatares y querellas dan cuenta de la fuerte disputa en torno al control de las ideas que se expresaban en la prensa y la importancia de la lucha por supervisar y someter la opinión pública. Es decir, la ferviente rivalidad entre distintos medios con visiones antagónicas, así como la compulsa entre diversos poderes por dominar los canales de comunicación refleja, a pesar del alto grado de analfabetismo en la época, el significativo impacto social e ideológico que los periódicos producían en la escena finisecular iberoamericana.

71 En simultáneo, una comisión de militares apeló al ministro de guerra exigiendo que se suprimieran varios periódicos y se aplicara el código de justicia militar a los delitos de imprenta. Aunque el gobierno no cedió ante esta demanda, tampoco se encontró en condiciones de ofrecer garantías a los periodistas ni condenar las agresiones ocurridas, por lo que terminó favoreciendo indirectamente a las posiciones militaristas. Pérez Ledesma, "La sociedad española, la guerra y la derrota", pp. 91-150. 


\section{Conclusiones}

A través de los párrafos anteriores hemos rastreado y demarcado el discurso que el periódico Patria emitió dirigiéndose a un destinatario preciso y con un fin particular: atraer a la comunidad española a la causa independentista. A su vez, no sólo delimitamos este mensaje específico entre la totalidad discursiva del medio, que en realidad apeló a un amplio y plural abanico de remitentes diferentes, sino que lo analizamos y destacamos sus principales cualidades. En paralelo al análisis crítico de Patria también hemos realizado un estudio de carácter comparativo, ya que abordamos sus puntos centrales en contraposición a lo pronunciado por la prensa peninsular de tendencia liberal-conservadora y alineada a la mirada oficial. Esta visión de conjunto la hemos armado a partir de la puesta en relación de distintos estudios específicos sobre los medios más influyentes de distintas regiones de España, abstrayendo las características comunes que los diversos autores han coincidido en señalar.

A pesar de que muchas de las notas periodísticas citadas y examinadas no fueron exactamente sincrónicas en el tiempo, pudimos establecer un diálogo entre las mismas, dando como resultado un intenso debate al girar en torno a los mismos tópicos e ideas, pero con perspectivas y concepciones diametralmente opuestas. Tanto Patria, en representación de la prensa revolucionaria, como la prensa reaccionaria a favor de la perpetuación del orden colonial, llevaron a cabo un esfuerzo por adoctrinar a sus lectores a través de la difusión de sus posicionamientos sobre determinadas cuestiones. Estas polémicas expresadas en la escena mediática del siglo XIX, monopolizada por la prensa escrita periódica, no hacen más que dejar al descubierto un choque ideológico entre dos pensamientos antitéticos.

Así, el órgano del PRC, bajo la pluma de Martí, trataba de encender la llama de rebeldía también en la comunidad ibérica, despertando la conciencia sobre las injusticias que la mayoría padecía bajo un gobierno considerado despótico, y enseñando las ventajas que podía ofrecer una república democrática tanto a cubanos como hispanos por igual. Mientras tanto, los medios oficialistas, representantes de la monarquía y de unos sectores económicos interesados en mantener el dominio sobre la Gran Antilla tal y como estaba, desdibujaban cual caricaturas a los combatientes cubanos y deshonraban su causa, negándole toda fundamentación. Por el contrario, criminalizaban la sublevación, y afirmaban que su veloz represión era una cuestión de supervivencia para el pueblo español, su bienestar económico y su armonía social.

Es importante recordar, como advertimos desde el principio, que éste representó el discurso hegemónico en España, pero no fue el único, sino que existieron otros contrarios a la guerra que respondieron a agrupaciones políticas y causas diversas. Estas voces disidentes, aunque minoritarias, no pueden menospreciarse en tanto ejercieron una crítica pública y emitieron un 
mensaje alternativo al de exacerbado patriotismo que el gobierno monárquico requería. Sin embargo, no nos ocupamos de ellos en esta ocasión dado que, consideramos, no tuvieron el mismo impacto en la realidad que las arengas provenientes de los sectores dominantes al no contar con representación en las cortes, tener sus órganos de prensa una difusión escasa y carecer de influencia real en el poder como para incidir efectivamente en el curso de los hechos. ${ }^{72}$

Al focalizar en los discursos que probablemente calaron más hondo en el pensamiento o inconsciente colectivo de la sociedad española, en tanto provenían de los periódicos con las mayores tiradas, hallamos ciertas alegorías e imágenes estereotipadas que difundieron los medios estudiados de forma generalizada. Por un lado, las referencias al pasado imperial triunfante, la gloria de sus soldados, la abnegación de su pueblo a la corona y la cruz, la patria sagrada y la supremacía cultural de la raza hispana, son parte del universo simbólico que se evoca constantemente en la mayoría de los diarios peninsulares. Mientras tanto, se divulga un concepto de los combatientes cubanos que los califica como rebeldes bárbaros y salvajes, que sólo persiguen fines vandálicos, haciendo caso omiso de todo el fundamento ideológico y de las bases populares sobre las que se sostenía el movimiento. Contemplamos cómo la vejación, el racismo y la discriminación de todo tipo se encontraban a la orden del día en los discursos que se proponían deslegitimar la lucha revolucionaria.

Sin embargo, estas apologías de la monarquía y de la preservación del imperio hispano no fueron infranqueables para la comunidad española, que resultó receptiva a otras voces opositoras que plantaron sus críticas y lograron atraer a ciertos sectores hispanos en la lucha por la independencia. Hemos visto cómo Patria se dirigió a ellos mediante un discurso específico y singular, consciente de la necesidad de clarificar conceptos, erradicar prejuicios y aspirar a su aquiescencia. Martí apuntó a transmitir que el combatiente cubano no era un Otro, ajeno y extraño, que había que exterminar porque deshonraba a la patria española, sino un ser que sufría tantas injusticias como los propios hispanos, muchas veces poco conscientes de las causas y el origen de su opresión.

A su vez, Patria también se encargó de reiterar constantemente que los cubanos consideraban a los españoles sus hermanos, que sabían distinguirlos del sistema colonial al que combatían y del que eran víctimas, asegurándoles

72 Tal es el caso por ejemplo de los socialistas, que manifestaron su oposición a la guerra a través del periódico El Socialista, o los republicanos federales agrupados en torno a Francisco Pi y Margal que se expresaron a través de El Nuevo Régimen (ambos semanarios tuvieron una difusión limitada). Hemos visto que algo parecido ocurrió con el anarquismo, que por sus conexiones internacionales e incidencia en la isla actuó como una fuerza combatiente considerable dentro de Cuba, pero no así al interior de la península. 
un lugar digno y en igualdad de condiciones en la futura República. Incontables editoriales fueron dedicadas a explicar y justificar por qué se iniciaba la revolución, considerada la última opción ante el fracaso de todas las demás alternativas, y a desarrollar el proyecto democrático que motorizaba la lucha por la emancipación. De esta forma, evidenciamos algunos de los nodos argumentativos claves que cimentaron su discurso proselitista, resultado de su vocación unificadora, con el fin de congregar a cubanos y españoles en torno a la ruptura colonial.

En consecuencia, aunque muchos medios hayan pretendido ocultarlo, un gran número de españoles se identificó con la lucha separatista, y varios se implicaron en ella militarmente. Por lo tanto, dicha participación evidenció cierta efectividad en la invocación e interpelación realizada por el grupo revolucionario que organizó la guerra. Sin menospreciar la incidencia de factores que escapan a lo puramente ideológico — como por ejemplo la apremiante necesidad de escapar de un servicio militar obligatorio en condiciones inhumanas - hemos puesto de relieve la importancia de la difusión de un discurso que supo ser amplio e inclusivo, conteniendo las necesidades y aspiraciones también de los grupos hispanos. Como resultado, apreciamos el papel elemental que en la guerra de Cuba han jugado los medios de comunicación, en este caso los periódicos, siendo una de las primeras experiencias históricas en la que la prensa ha adquirido tal protagonismo.

En efecto, sostenemos la idea de que, tanto la prensa cubana separatista como la prensa española oficial han sido ambas condiciones de posibilidad para el inicio y desarrollo de la contienda, predicando ideologías y sistemas políticos opuestos, e impulsando a su público lector a luchar para defenderlos. Asistimos a una situación inédita en la que los medios de comunicación periodísticos adquirieron un especial poder para configurar opiniones $\mathrm{y}$, por ende, no sólo transmitir una imagen determinada de la realidad, sino también impactar sobre la misma. A lo largo de todo el artículo intentamos evidenciar esta eficiencia que la prensa ha logrado a través de su interpretación y de su actuación: es decir, ésta no sólo ejerció como fuente, sino también como agente, ya que a partir de la difusión de su propia versión de la situación y de su rol de ideologización incidió en la toma de posiciones, adhesiones y acciones, tanto en nombre de un orgullo nacional e imperial pretérito, como de un nacionalismo emergente con ansias de libertad.

\section{REFERENCIAS}

Alonso Valdés, Coralía. La inmigración española en Cuba como fuerza de trabajo: 1800-1933, La Habana: Ministerio de Ciencia, Tecnología y Medio Ambiente. Archivo Nacional de Cuba, 2000. 
Blanco Rodríguez, Juan Andres y Alonso Valdés Coralía, Presencia castellana en el "ejército libertador cubano" (1895-1898), España, Junta de Castilla y León, Consejería de Educación y Cultura, Uned Zamora, 1996.

Bueno, Salvador, José Martí y su periódico Patria, Puvill Libros, 1997.

Casanovas Codina, Joan, "Movimiento obrero y lucha anticolonial en Cuba después de la abolición de la esclavitud", Boletín Americanista, núm. 45, 1995, pp. 23-41.

Casanovas Codina, Joan, ;O pan, o plomo! Los trabajadores urbanos y el colonialismo español en Cuba, 1850-1898, Madrid, Siglo veintiuno de España Editores, 2000.

Dueñas Becerra, Jesús, “José Martí, el periódico Patria y el periodismo revolucionario”, 14 de marzo de 2017. http://uneac.org.cu/noticias/jose-marti-el-periodicopatria-y-el-periodismo-revolucionario

Erice Sebares, Francisco, "Los asturianos ante la guerra de Cuba (1895-1898)", ENTEMU-, vol. XVII, Aportaciones a cinco siglos de la Historia Militar de España, 2013, pp. 147-164.

Fernández Expósito, José Raúl; Cabrera Acosta, Miguel Angel y González, Ramón Felipe, La prensa burguesa en Canarias ante la guerra de Cuba, Santa Cruz de Tenerife, Centro de la Cultura Popular Canaria, 1986.

García Luis, Julio, "Volver a leer a Patria: 1892-1992”, Revista Bohemia, La Habana, 13 marzo de 1992, pp. 4-7.

Ibarra Cuesta, "La guerra del 95: ¿la guerra de la voluntad y del ideal o de la necesidad y de la pobreza?", en Salvador Broseta, Las ciudades y la guerra: 1750-1898, 2002, pp. 451-470.

Martínez de Salinas Alonso, María Luisa. Noticias de Cuba. Cartas de emigrantes vallisoletanos en la segunda mitad del siglo XIX, Valladolid, Universidad de Valladolid. Instituto Interuniversitario de Estudios de Iberoamérica y Portugal, 2007.

Medina Hernández, Ileana, "Cuba, Canarias y la prensa, en el contexto del 98", Revista Latina de Comunicación Social, núm. 6, 1998. Recuperado el 22 de marzo de 2020 de http://www.ull.es/publicaciones/latina/a/82ile.htm

Meléndez, Edgardo, Puerto Rico en Patria, Universidad de Puerto Rico, 1996.

Moreno Fraginals y Moreno Maso, Guerra, migración y muerte (el ejército español en Cuba como vía migratoria), Gijón, España, 1993.

Pérez Ledesma, Manuel, "La sociedad española, la guerra y la derrota", Más se perdió en Cuba. España, 1898 y la crisis de fin de siglo, de Juan Pan-Montojo, Madrid, Alianza Editorial, 1998, pp. 91-150.

Pérez Murillo, María Dolores, Cartas de emigrantes escritas desde Cuba. Estudio de las mentalidades y valores en el siglo XIX, Cádiz-Sevilla, Aconcagua libros (Sevilla) y Universidad de Cádiz, 1999.

Pérez Suárez Adalys, "Patria, emblema del periodismo cubano", 14 de marzo de 2017, en http://uneac.org.cu/noticias/patria-emblema-del-periodismo-cubano

Piñeiro-Otero, Teresa, "Héroes, filibusteros y villanos. Representaciones y mitos de la Guerra de Cuba en la prensa gallega del momento (1895-1898)", Historia y Comunicación Social, vol. 16, 2011, pp. 111-130.

DOI: https://doi.org/10.5209/rev_HICS.2011.v16.37153 
Ratuschny, Aldana, El periódico Patria como mediación revolucionaria en el proceso de Independencia en Cuba. Tesis de Grado de Licenciatura en Historia, Departamento de Humanidades, Universidad Nacional del Sur, Argentina, 2018.

Ratuschny, Aldana, José Martí y el periodismo revolucionario: los inicios del periódico Patria (1892-1893), Tesis de Máster, Facultad de Filosofía y Letras, Universidad de Valladolid, España, 2019.

Ripoll, Carlos, Patria: el periódico de José Martí: registro general de 1892-1895, New York, Eliseo Torres and Sons, 1971.

Sanabia, Diony, "Patria, periódico de José Martí desde EUA", 18 de marzo de 2017. http://operamundi.uol.com.br/dialogosdelsur/patria-periodico-de-jose-martidesdeeua/18032017/)

Sevilla Soler, Rosario, La Guerra de Cuba y la Memoria Colectiva. La crisis del 98 en la prensa sevillana, Sevilla, Escuela de Estudios Hispano-Americanos-CSIC, 1996.

Suárez León, Carmen, "Comentarios al periódico Patria", Instituto Cubano del Libro, Edición especial. Centenario de Patria, 1992, p. 29.

Toledo Sande, Luis, "José Martí, el don de la propaganda", 12 de mayo del 2014. roa.ult.edu.cu/bitstream/123456789/2424/1/Marti.doc

Tornero, Pablo, "Desigualdad y racismo. Demografía y sociedad en Cuba a fines de la época colonial", Revista de Indias, vol. LVIII, núm. 212, 1998, pp. 25-46. DOI: https://doi.org/10.3989/revindias.1998.i212.763

Villalobos Jiménez, Alfredo, "La misión del periodismo en José Martí, InterSedes: Revista de las Sedes Regionales, vol. XI, núm. 21, 2010, pp. 136-146. 